\title{
Characteristics of the Precipitation Diurnal Variation and Underlying Mechanisms Over Jiangsu, Eastern China, During Warm Season
}

\author{
Xiyu Mu ${ }^{1}$, Anning Huang ${ }^{2 *}$, Yang $W^{2}{ }^{2}$, Qi X ${ }^{3}{ }^{3}$, Yuanyuan Zheng ${ }^{1}$, Huijuan Lin ${ }^{4}$, Dexian Fang ${ }^{5}$, \\ Xindan Zhang ${ }^{2}$, Yong Tang $^{2}$ and Shuxin $\mathrm{Cai}^{2}$ \\ ${ }^{1}$ Key Laboratory of Transportation Meteorology, China Meteorological Administration, Jiangsu Institute of Meteorological \\ Sciences, Nanjing Joint Institute for Atmospheric Sciences, Nanjing, China, ${ }^{2}$ CMA-NJU Joint Laboratory for Climate Prediction \\ Studies and State Key Laboratory of Severe Weather and Joint Center for Atmospheric Radar Research of CMA/NJU, School of \\ Atmospheric Sciences, Nanjing University, Nanjing, China, ${ }^{3}$ Jiangsu Air Traffic Management Branch Bureau of CAAC, Nanjing, \\ China, ${ }^{4}$ Suzhou Meteorological Burea, Suzhou, China, ${ }^{5}$ Chongqing Yubei Meteorological Burea, Chongqing, China
}

OPEN ACCESS

Edited by:

Raquel Nieto,

University of Vigo, Spain

Reviewed by:

Yuan Sun,

National University of Defense

Technology, China

Ashok Kumar Jaswal,

India Meteorological Department,

India

Jian Li,

Chinese Academy of Meteorological Sciences, China

*Correspondence: Anning Huang

anhuang@nju.edu.cn

Specialty section: This article was submitted to

Atmospheric Science,

a section of the journal

Frontiers in Earth Science

Received: 30 April 2021

Accepted: 05 July 2021

Published: 16 August 2021

Citation:

Mu X, Huang A, Wu Y, Xu Q, Zheng $Y$, Lin $H$, Fang $D$, Zhang $X$, Tang $Y$ and Cai S (2021) Characteristics of the

Precipitation Diurnal Variation and Underlying Mechanisms Over Jiangsu, Eastern China, During Warm Season.

Front. Earth Sci. 9:703071. doi: 10.3389/feart.2021.703071
Based on the hourly precipitation observed from 1800 automatic rain gauges during 2013-2017, characteristics of precipitation diurnal variation and underlying mechanisms over Jiangsu Province, eastern China, during the warm season (May to September) have been revealed in this study. Results show that the precipitation amount (PA), frequency (PF), and intensity (PI) are zonally distributed over Jiangsu. The precipitation shows distinct diurnal cycle and zonal distribution. The large precipitation is located over the southwest side of the Jiangsu section of Yangtze River (JSYR). From midnight to noon, the precipitation expands northeastward, but the precipitation shrinks southeastward from noon to midnight. Meanwhile, the PA is larger during the daytime than that during the nighttime over most Jiangsu. In addition, the PA shows two diurnal peaks, with one in the early morning mainly resulting from the long-duration rainfall and the other in the afternoon resulting from the short-duration rainfall. The total rainfall is largely contributed by the long-duration rainfall. During the whole warm season, water vapor convergence (divergence) and ascending (sinking) movements are consistent, corresponding to the long-duration precipitation diurnal cycles. The contribution of rainfall with long (short) duration to the total rainfall over most areas shows very distinct sub-seasonal variations with a clear decreasing (increasing) trend from pre-Meiyu through Meiyu to post-Meiyu. Among the three subperiods in a warm season, the PA and diurnal cycle of the total rainfall are mostly contributed by those during the Meiyu period. The long-duration precipitation is closely related to the enhancement of the water vapor convergence during the pre-Meiyu period. However, during the Meiyu and post-Meiyu periods, the long-duration precipitation is more consistent with the dynamic lift since the water vapor is abundant. Concluded from the cluster analysis, precipitation spatial distributions are closely associated with the underlying surface, such as the Yangtze River, big cities, Lake Taihu, Lake Hongze, and complex coastal lines. The diurnal variation of the rainfall over different underlying surfaces shows respective diurnal cycle features.

Keywords: precipitation diurnal cycle, underlying surface, different durations of rainfall, warm season, Jiangsu of eastern China 


\section{INTRODUCTION}

The diurnal cycles of precipitation have been systematically investigated in various regions of the world during the recent years (Dai, 2001; Svensson and Jakob, 2002; Twardosz, 2007; Kikuchi and Wang, 2008; Yaqub et al., 2011; Yuan et al., 2013; Bowman and Fowler, 2015; Yokoi et al., 2017). Investigating the diurnal cycle of precipitation is important to understand the physical mechanisms of precipitation formation and local climate, and further to better predict regional precipitation events and improve climate models (Dai et al., 1999; Carbone et al., 2002; Sato et al., 2009; Surcel et al., 2010; Yuan, 2013; Xue et al., 2018). Previous studies have shown that the precipitation diurnal cycle has distinct spatial and seasonal variations (Dai, 2001; Mao and Wu, 2012). Oceanic precipitation usually peaks in the early morning, while the continental precipitation tends to peak in the evening. The late night to early morning precipitation maximum is mostly found in the leeward areas of mountains, basins, valleys, and coastal areas (Ohsawa et al., 2001; Yang and Slingo, 2001; Ogino et al., 2016).

Previous studies on precipitation diurnal cycles over China have made a great progress. Summer precipitation over China shows evident diurnal variations with considerable regional features (Yu et al., 2007a; Zhou et al., 2008; Yu et al., 2014). Along the Yangtze River Basin, the summer precipitation diurnal cycles show eastward delaying peak time with a midnight maximum in the upper valley, an early morning peak in the middle valley, and a late afternoon maximum in the lower valley (Chen et al., 2010; Wu et al., 2018). The summer precipitation over the region between the Yangtze and Yellow rivers exhibits two diurnal peaks, with one in the early morning and the other in the late afternoon (Yu et al., 2007a). Over the Northern China Plains, the summer precipitation shows a diurnal peak in the afternoon near the top of the mountain ranges and propagates southeastward with a diurnal peak during midnight and early morning over the central Northern China Plains (He and Zhang, 2010), while the precipitation displays two diurnal peaks, with one in the early morning and the other in the late afternoon over Southern China (Li et al., 2010; Jiang et al., 2017) during the warm season.

Many recent studies have revealed that the diurnal variations of precipitation over eastern China are strongly influenced by the East Asia monsoon and topographic contrast. Over southeastern China, the spatial distributions of precipitation diurnal cycles in midsummer are primarily dependent on topography (Chen et al., 2010; Zhang et al., 2017; Wu et al., 2018). Over Shandong Province of eastern China, the precipitation over the inland areas strengthens in the afternoon due to the sea breeze, which may enhance the afternoon peak of precipitation. The precipitation diurnal peak in the afternoon appears earlier in the coastal northern plain than in the central northern plain (Zhuo et al., 2014). Over Fujian Province of southeastern China, the precipitation diurnal cycles are different among the coastal, valley, hilly, and mountainous areas during pre-summer (Zhang et al., 2017). The precipitation diurnal variation over Taiwan in the warm season is the result of local forcing involving solar thermal heating and island-scale land-sea breezes interacting with orography (Chen et al., 2012; Huang and Wang, 2014; Huang and Chang, 2018). Around the Indochina Peninsula, the occurrence time of the diurnal precipitation maximum in the warm season is largely affected by the local land use and land cover changes (Takahashi et al., 2010).

A set of data collected from rain gauges, satellites, radars, and reanalysis have been extensively used to investigate the precipitation diurnal cycles over China at meso-synoptic scales (Yu et al., 2007a, b; Li et al., 2008; Zhou et al., 2008; Chen et al., 2009a; Chen et al., 2009b; Chen C. S. et al., 2013; Yuan et al., 2010; Bao et al., 2011; Chen et al., 2012). However, the detailed characteristics of precipitation diurnal variation in Jiangsu Province and their relationship with the underlying surface are limited due to the insufficiency of rainfall observation with a high spatiotemporal resolution. Jiangsu Province, which is located in the lower reaches of the Yangtze River Valley and west to the Yellow Sea, is the lowest-lying province in China and belongs to the transitional climate zone from the subtropical to the temperate zone separated by the Huaihe River. The terrain heights of most areas are lower than $50 \mathrm{~m}$, with low mountains and hills concentrated in the southwest and north sides (Figure 1). The Yangtze River is located in the south of Jiangsu, and the Huaihe River is situated in the central Jiangsu. Meanwhile, there are more than 290 lakes, and 12 of them are larger than $50 \mathrm{~km}^{2}$, such as the Lake Taihu (in the southeast) with an area of $2,250 \mathrm{~km}^{2}$ and the Lake Hongze (in the northwest) with an area of $2,069 \mathrm{~km}^{2}$. Also, there are two big cities in Jiangsu, one is Nanjing located in the southwest Jiangsu (over the west end of Jiangsu section of Yangtze River, JSYR) and the other is Suzhou located in the southeast Jiangsu (over the east side of Lake Taihu).

As mentioned above, the underlying surface is complex in Jiangsu, including a large number of lakes, big cities, and coastal regions. This work uses high-resolution rain gauge data to highlight the fine features of precipitation diurnal variation, and the corresponding relationship with the underlying surface and synoptic background in the warm season (May to September), to clarify the probable reason for precipitation diurnal variation caused by the underlying surface and the synoptic thermal and dynamic factors, and to provide a reference for further improving the precipitation forecasting skills of the numerical models.

The remainder of the article is organized as follows: the datasets and methods used in this study are introduced in Data and Method. The characteristics of diurnal variation of precipitation amount (PA), frequency (PF), and intensity (PI) over Jiangsu during the warm season and their relationships with the distributions of the underlying surface and synoptic background are shown in Results and Analysis. The typical patterns of precipitation diurnal variation identified by the cluster analysis are given in Summary and Discussion. The conclusions and discussions are provided in Data Availability Statement.

\section{DATA AND METHOD}

\section{Data}

As the large-scale deployment of rain gauge stations over Jiangsu started from 2013 and the data after 2017 are unavailable at 


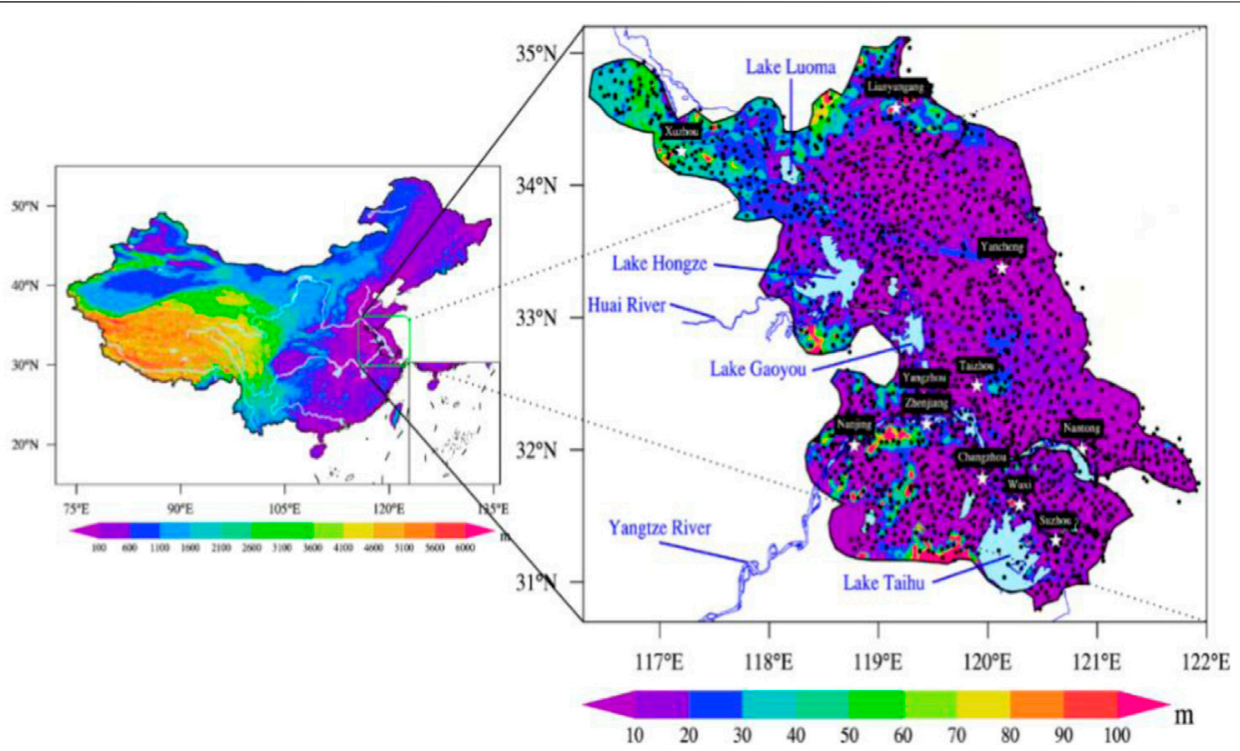

FIGURE 1 | The surface elevation (shaded) and rain gauges locations (dots) in Jiangsu. The left figure is the map of China and the location of study area. The right figure is a detailed map of Jiangsu Province.

present, the hourly rainfall data collected from 1,847 rain gauges over Jiangsu (Figure 1) from May to September during 2013-2017 are used in the current study. The data are provided by the Jiangsu Meteorological Bureau of China. The mean resolution of rain gauges is $\sim 8 \mathrm{~km}$ and even less than $5 \mathrm{~km}$ in south Jiangsu, and the gauge rainfall data with much higher resolution are good for investigating the detailed characteristics of the precipitation diurnal variation (Yang et al., 2013; Xue et al., 2018). The data quality is controlled by the extreme values of precipitation and the consistency of the precipitation records following $\mathrm{Yu}$ et al. (2007b) and Wu et al. (2018). In addition, the hourly ERA5 data with the spatial horizontal resolution of $0.25^{\circ} \times 0.25^{\circ}$ (https://www.ecmwf.int/en/forecasts/datasets/reanalysis-datasets/ era5) are also used to address the possible mechanisms related to the diurnal cycle of precipitation in this study.

\section{Method}

During the warm season (May to September) over 2013-2017, the total hours at each rain gauge station are $153 \times 5 \times 24=18,360 \mathrm{~h}$. The precipitation hour is defined when the measurable precipitation $\geqslant 0.1 \mathrm{~mm} \mathrm{~h}^{-1}$. Corresponding to the observation data, the minimum precipitation for all figures is set to $0.1 \mathrm{~mm} \mathrm{~h}^{-1}$. Following Wu et al. (2018), the PA (accumulated precipitation divided by the total hours), $\mathrm{PF}$ (the percentage of the total precipitation hours to the total hours), and PI (the accumulated precipitation divided by the total precipitating hours) for each hour of a day at each station can be calculated. In addition, the duration of precipitation is defined as the number of hours between the start and end of a continuous rainfall during which the precipitation is not less than $0.1 \mathrm{~mm} \cdot \mathrm{h}^{-1}$ at each hour (Yu, 2007b; Li et al., 2008; Wu et al., 2018). Based on different precipitation durations, the rainfall events are divided into short-duration $(\leq 6 \mathrm{~h})$ and long-duration
(>6 h) rainfall events (Yu, 2007b). To reveal the sub-seasonal variation of the precipitation diurnal cycles, the warm season is further divided into three subperiods, including pre-Meiyu (May $1^{\text {st }} \sim$ June $14^{\text {th }}$ ), Meiyu (June $15^{\text {th }} \sim$ July $15^{\text {th }}$ ), and post-Meiyu (July $16^{\text {th }} \sim \operatorname{Sep~} 30^{\text {th }}$ ) periods according to the local climate (Ding, 1992).

To characterize the representative patterns of the diurnal cycle and spatial distribution of precipitation in Jiangsu, the $24 \mathrm{~h}$ time series of the hourly climatic mean PA, PF, and PI normalized by their daily mean at each station are subjected to harmonic analysis by the method mentioned by Dai (2001), Yin et al. (2009), and Zhang et al. (2017). The diurnal peak off PA (PPA) is defined as the largest value of the $24 \mathrm{~h}$ time series of the hourly climatic mean PA. The first three harmonic components are obtained to show the diurnal cycle. Stations with the sum of the first three harmonic components contributing more than $65 \%$ of the total daily variance are selected to further conduct the cluster analysis. Then, the fuzzy C-means cluster analysis by Fujibe (1999), Zhang et al. (2017), and Wu et al. (2018) is adopted to detect the representative patterns of precipitation diurnal variation.

\section{RESULTS AND ANALYSIS}

\section{Spatial Distributions and Sub-Seasonal Variations of PA, PF, and PI}

Figure 2 gives the spatial distribution of the climatic mean PA, $\mathrm{PF}$, and PI for the total rainfall and the rainfall with different durations in the warm season. The climatic PA, PF, and PI of the total rainfall tend to show quasi-zonal characteristics (Figures $\mathbf{2 A}, \mathbf{D}$, and G). A relatively larger PA $\left(>0.3 \mathrm{~mm} \mathrm{~h}^{-1}\right)$ for the total rainfall is mainly located along the south side of JSYR and 

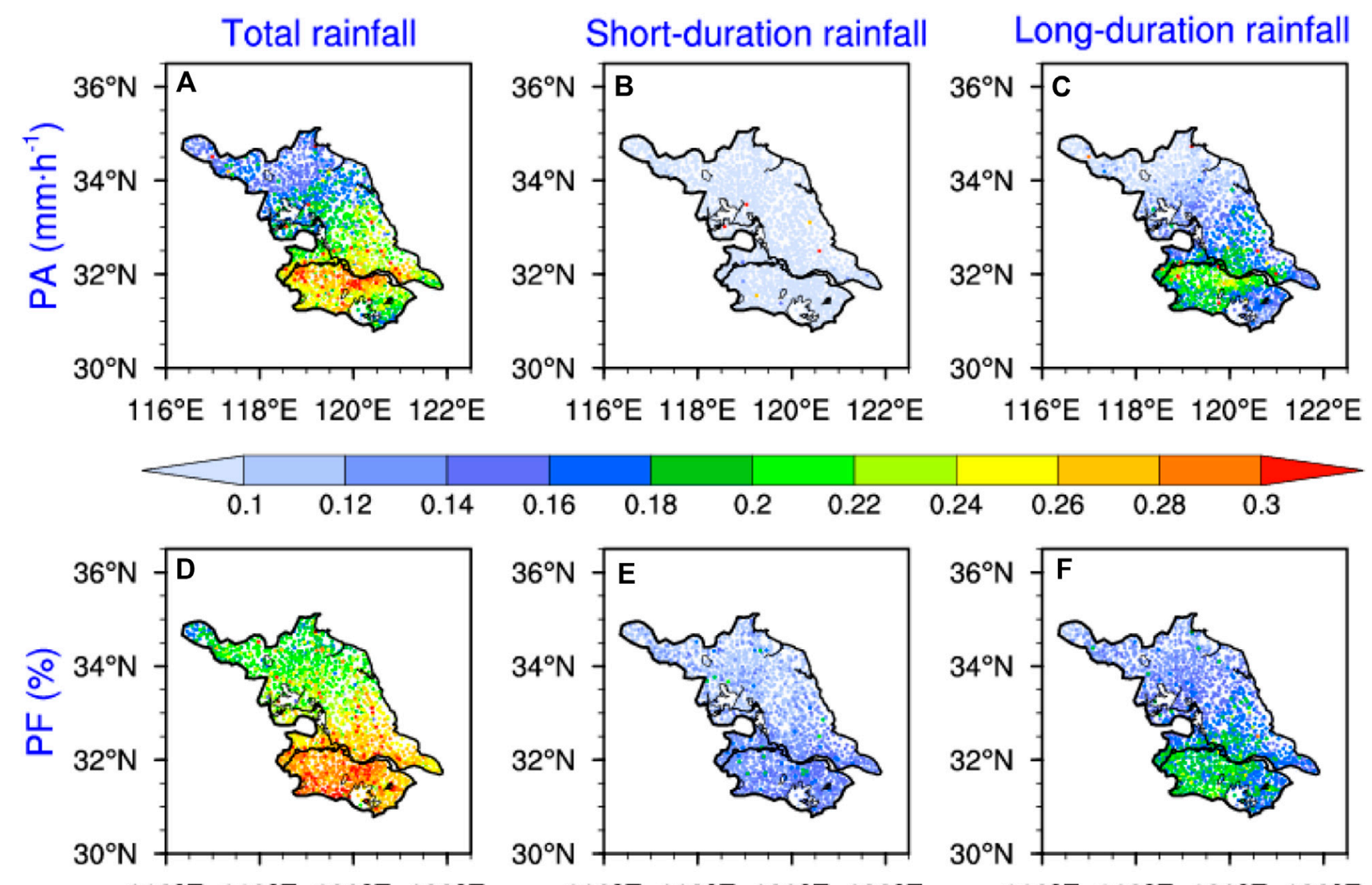

$116^{\circ} \mathrm{E} 118^{\circ} \mathrm{E} 120^{\circ} \mathrm{E} 122^{\circ} \mathrm{E}$

$116^{\circ} \mathrm{E} 118^{\circ} \mathrm{E} 120^{\circ} \mathrm{E} 122^{\circ} \mathrm{E}$

$116^{\circ} \mathrm{E} 118^{\circ} \mathrm{E} 120^{\circ} \mathrm{E} 122^{\circ} \mathrm{E}$
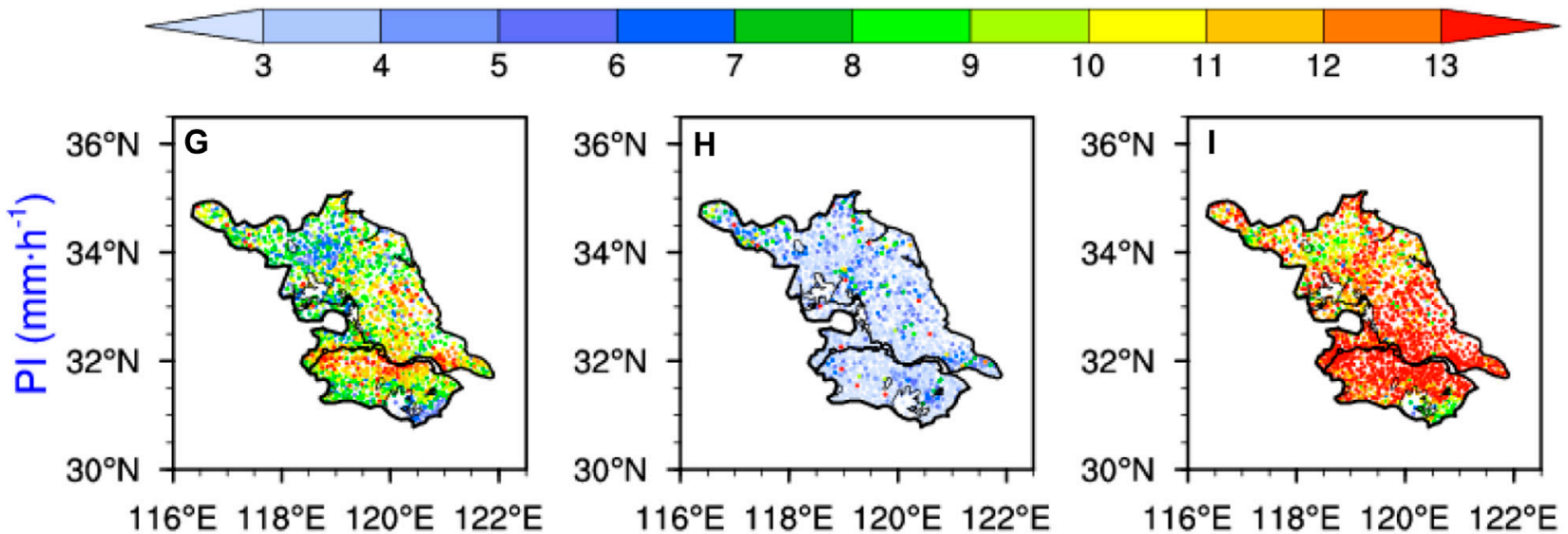

$116^{\circ} \mathrm{E} 118^{\circ} \mathrm{E} 120^{\circ} \mathrm{E} 122^{\circ} \mathrm{E}$

$116^{\circ} \mathrm{E} 118^{\circ} \mathrm{E} 120^{\circ} \mathrm{E} 122^{\circ} \mathrm{E}$

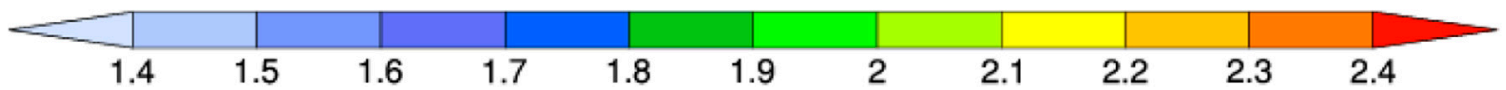

FIGURE 2 | Spatial distributions of PA (A-C), PF (D-F) and PI (G-I) for the rainfall with different duration time in warm season (three columns separately represent total rainfall, short-duration rainfall and long-duration rainfall) averaged over 2013-2017.

gradually decreases on both sides (Figure 2A). The PF for the total rainfall (Figure 2D) overall zonally distributes with a gradually northward decreasing and a much higher PF (>13\%) located over the south of JSYR. The spatial distribution of PI of the total rainfall (Figure 2G) is similar to that of the PA (Figure 2A). Comparing the distribution of the rainfall with a short (Figures 2B, E, and I) and long duration (Figures 2C, F, and $\mathbf{J}$ ) with the total rainfall, the total rainfall is mainly contributed by the long-duration rainfall (Figures 2C, F, and $\mathbf{H}$ ).

Figure 3 further gives the spatial distributions of the PA for the total rainfall and rainfall with different durations in the three subperiods of the warm season. As shown in Figures 3A, 

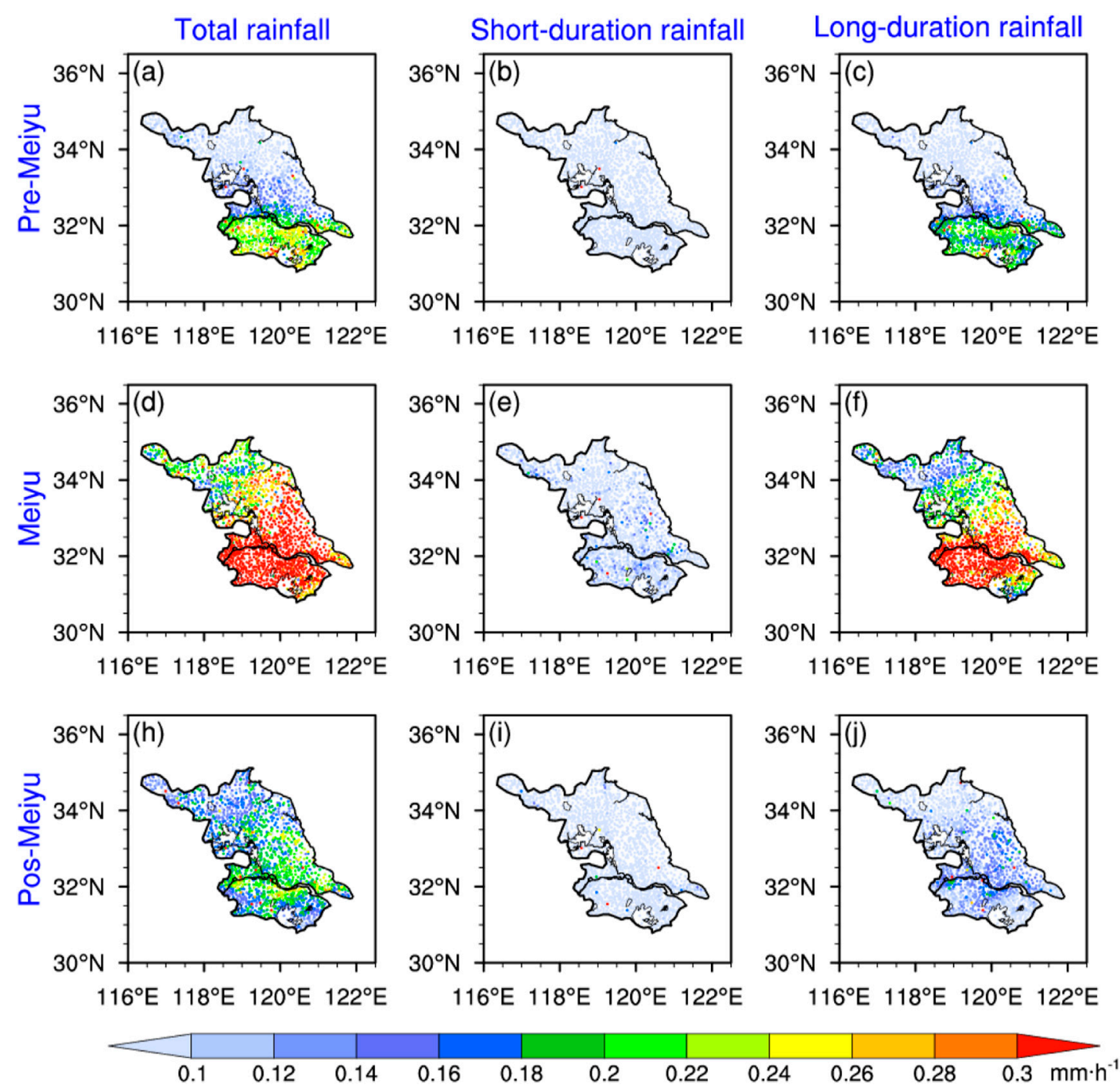

FIGURE 3 | Spatial distributions of PA for the total rainfall (A,D,H), short-duration rainfall (B,E,I) and long-duration rainfall (C,F,J) in each sub-period of warm season (three rows separately represent Pre-Meiyu, Meiyu and Post-Meiyu period) averaged over 2013-2017.

$D$, and $\mathbf{H}$, the PA of the total rainfall displays apparent subseasonal variation from the pre-Meiyu through Meiyu to the post-Meiyu period with the rain belt moving northward corresponding to the northward shift of East Asian summer monsoon. Among the three subperiods, the strongest PA with the intensity of more than $0.28 \mathrm{~mm} \mathrm{~h}^{-1}$ over most Jiangsu occurs during the Meiyu period caused by the local main rainy season (Ding, 1992).

The rainfall with a long duration (Figures 3C, F, and J) shows a similar spatial pattern to the total rainfall during each subperiod. In addition, the PA of long duration exhibits a much larger sub-seasonal variation than that of the short duration (Figures 3B, E, and I) and deminants the subseasonal variation of the PA of the total rainfall. Compared to the PA of the long-duration rainfall, the PA of short duration shows a much weaker spatial variation during each subperiod
(Figures 3B, E, and I). Generally, the short-duration rainfall is closely related to the local thermal condition associated with the underlying surface such as hills, valleys, lakes, and cities (Zhang et al., 2017; Wu et al., 2018). And the long-duration rainfall is closely related to the large-scale atmospheric circulation, such as monsoonal circulation (Chen et al., 2010; Wu et al., 2018). Meanwhile, the short-duration rainfall mainly concentrates over some prevailing downwind regions with a relatively larger thermal contrast. For example, the short-duration rainfall strengthens about $30-40 \%$ over the northeast side of Lake Taihu due to the enhanced ascending induced by the thermal contrast between the urban region and lake area imbedded in the southerly summer monsoon winds (Tang et al., 2016).

As shown in Figure 4, the long-duration rainfall contributes more than $60 \%$ of the total rainfall over most Jiangsu regions, and more than $75 \%$ over the southwestern and part of central Jiangsu 

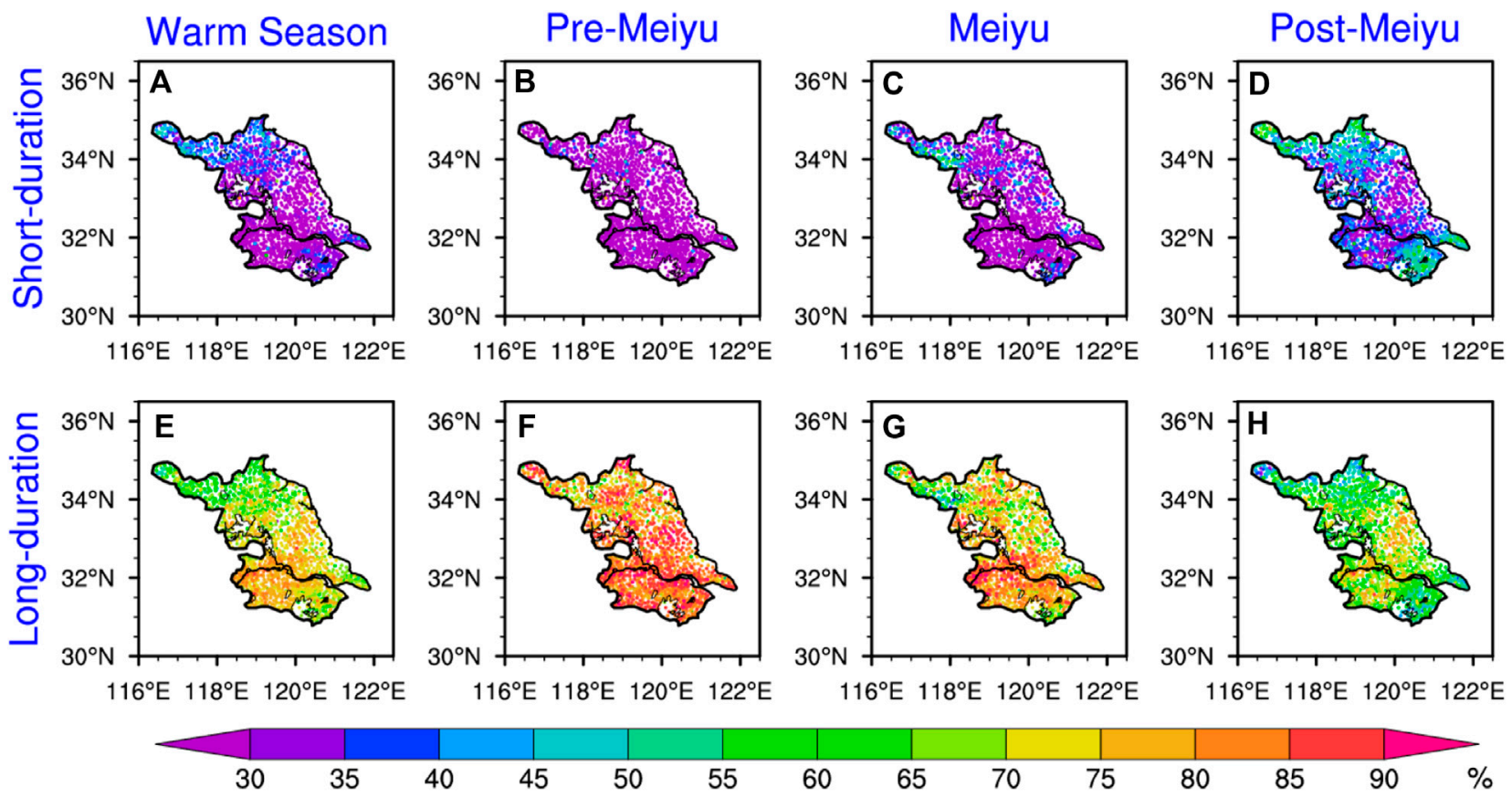

40

45

$50 \quad 55$

60

65

75

FIGURE 4 | Contribution of the short-duration rainfall (A-D) and long-duration rainfall (E-H) in warm season and each sub-period of warm season (four rows separately represent Warm season, Pre-Meiyu, Meiyu and Post-Meiyu period) over 2013-2017.

for the entire warm season (Figure 4E). Compared to the longduration precipitation, the short-duration rainfall mainly affected by the underlying surface thermal conditions contributes much less to the total rainfall (Figure 4A). The contribution of the short-duration rainfall $(\sim 40 \%)$ is relatively larger over northern Jiangsu with higher terrains and the areas east to large lakes, such as Lake Hongze and Lake Taihu. Yet, the short-duration rainfall contributes less to the total rainfall over the southwestern and central Jiangsu with values smaller than $30 \%$. Similar to the whole warm season, the total rainfall in each sub-period is largely determined by the long-duration rainfall (Figures 4B-D and F-H). Meanwhile, the contribution of the rainfall with long (short) duration to the total rainfall over most areas shows very distinctive sub-seasonal variation with a clear decreasing (increasing) trend from pre-Meiyu through Meiyu to post-Meiyu (Figures 4B-D and F-H). In addition, a relatively larger contribution of short-duration rainfall to the total rainfall in the post-Meiyu period is located over the hilly regions in the north and southeast Jiangsu, regions east to Lake Taihu and lower valley of JSYR (Figure 4D), where the contribution ranges from 35 to $50 \%$.

The spatial distributions of the PA and PF show zonal characteristics with a northward decrease over Jiangsu Province during the warm season. The large PA (PF) center is located over the southwest side of JSYR (big cities and the southwestern hilly areas). The strong PI center is located over the south side of JSYR, with relatively higher values over the coastal area. The precipitation of the total rainfall is strongly influenced by the Meiyu rainfall during the warm season. The climatic mean PA shows significant diurnal and spatial variations.

\section{Precipitation Diurnal Cycles and Their Sub-Seasonal Variations in the Warm Season}

Figure 5 shows spatial distributions of the climatic mean PA averaged every $3 \mathrm{~h}$. The PA exhibits distinctively diurnal variations. A small rainfall center with the PA over $0.2 \mathrm{~mm} \mathrm{~h}^{-1}$ is located at the east end of JSYR during 00:00-03: 00 BJT (Figure 5A). This rainfall center rapidly expands westward and northward and intensifies from 03:00BJT to 09: 00 BJT (Figures 5B, C). Then the PA increases to $0.3 \mathrm{~mm} \mathrm{~h}^{-1}$ over most southwestern Jiangsu and maintains during 09:00-18: 00BJT (Figures 5E, F). During 15:00 BJT to midnight (Figures $5 \mathrm{~A}-\mathbf{F})$, the range of rainfall center with the $\mathrm{PA}$ over $0.2 \mathrm{~mm} \mathrm{~h}^{-1}$ gradually shrinks eastward and southward as the PA gradually decreases. During 21:00-00:00BJT (Figure 5H), the rainfall center with the PA over $0.2 \mathrm{~mm} \mathrm{~h}^{-1}$ is located over the regions south to JSYR.

Figures 6A, B further show the spatial distribution of the PA during daytime (08:00BJT-20:00BJT) and nighttime (20:00BJT08:00BJT). Both daytime and nighttime PA show a very similar spatial pattern to the total PA (Figure 2A), which displays a quasi-zonal distribution with a relatively larger PA located along the south side of JSYR with southward and northward decreasing trends. In addition, the ratios of the daytime PA to the nighttime PA during the whole warm season (Figure 6C) are larger than 1.0 over most Jiangsu, except for some small areas in north Jiangsu, indicating that the daytime PA is higher than the nighttime PA over most Jiangsu in the warm season. Especially over most areas between $31.5^{\circ} \mathrm{N}$ and $33^{\circ} \mathrm{N}$ and the regions east to the south of 


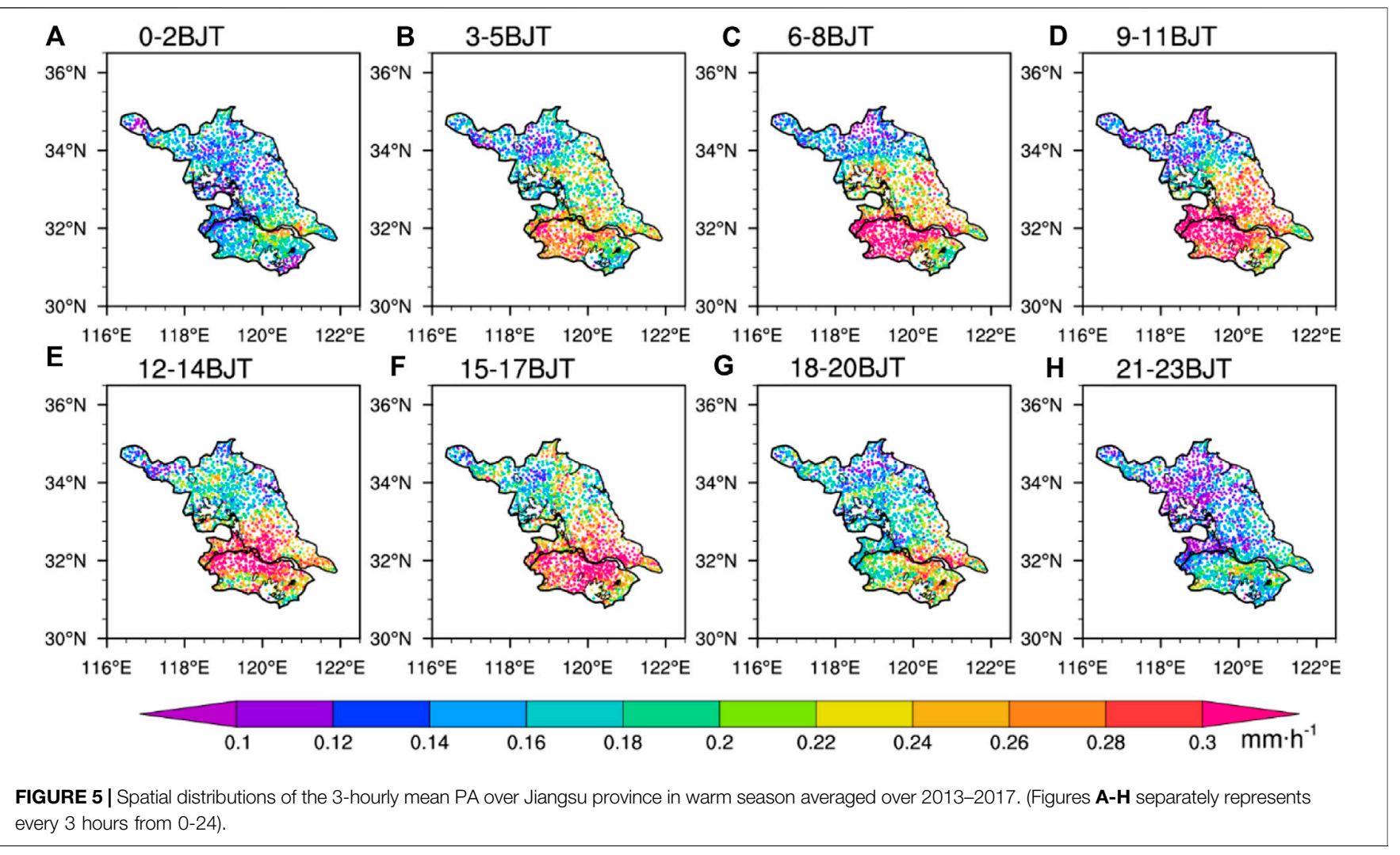

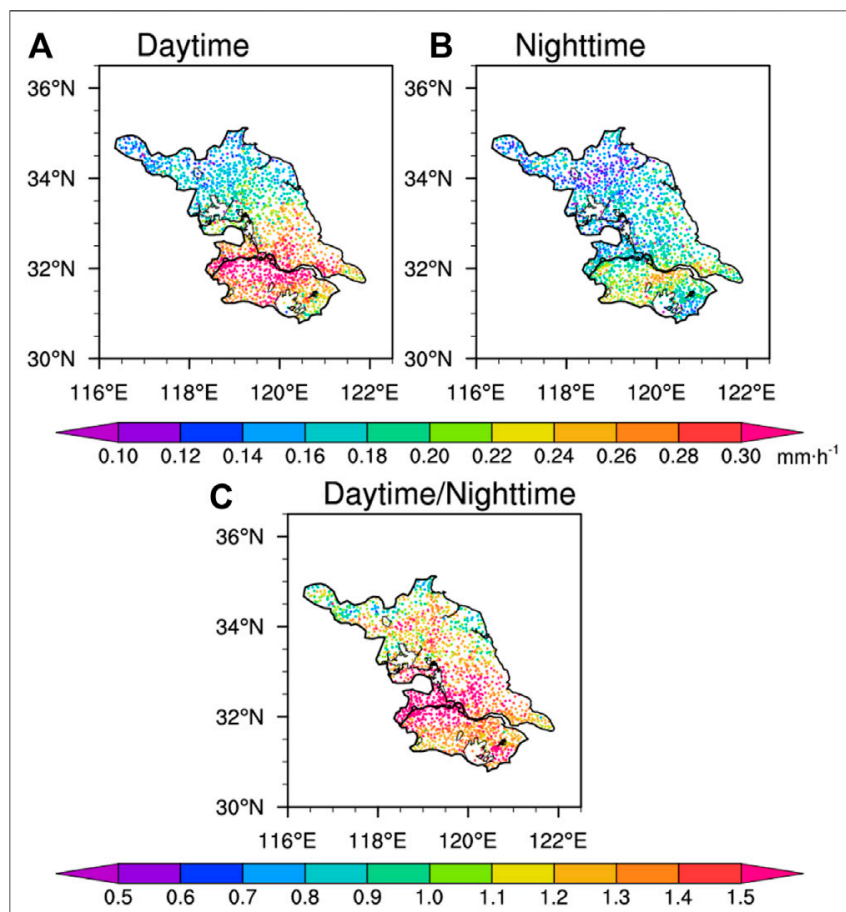

FIGURE 6 | Spatial distributions of daytime (0800-20:00 BJT) PA (A), nighttime (2000-0800 BJT the next day) PA (B), and (C) the ratio of daytime PA to nighttime PA in the warm season averaged over 2013-2017.
Lake Taihu, the ratios are larger than 1.5 , suggesting that the total rainfall over these areas is largely determined (more than $60 \%$ ) by the daytime precipitation.

Figure 7 gives the precipitation diurnal variability (PDV) indicating the diurnal amplitudes (Brito and Oyama, 2014; Zhang et al., 2017) during each subperiod. The relatively larger PDV $(>40 \%)$ for the total rainfall (Figure 7A) is located over the west end of JSYR (known as Nanjing City) and some sporadic hill areas in north Jiangsu, while the relatively larger PDV $(>60 \%)$ during pre-Meiyu and post-Meiyu periods is mainly located over the west end of JSYR (Figures 7B, D). However, much stronger PDV (>80\%) is located over north Jiangsu during the Meiyu period (Figure 7C), corresponding to the underlying surfaces with Lake Hongze and hills. PDV of the total rainfall is also higher over the east side of lakes Hongze and Taihu than that over their surrounding areas during each period (Figures 7A-D). PDV of the short-duration rainfall shows a slightly spatial variation during pre-Meiyu and Meiyu periods. But during the post-Meiyu period, it is higher over Nanjing City, Suzhou City, and east side of Lake Hongze, and lower over some coastal and hill regions (Figures 7E-H). Meanwhile, PDV of the rainfall with long duration (Figure 7I-L) exhibits a similar spatial distribution to PDV of the total rainfall (Figures 7A-D) during each period but shows much higher values. Overall, PDV of the total rainfall is largely determined by the long-duration rainfall.

Figures 8, 9 further show the spatial distributions of the diurnal peak of the PA (PPA) and its occurrence time for the total, long 

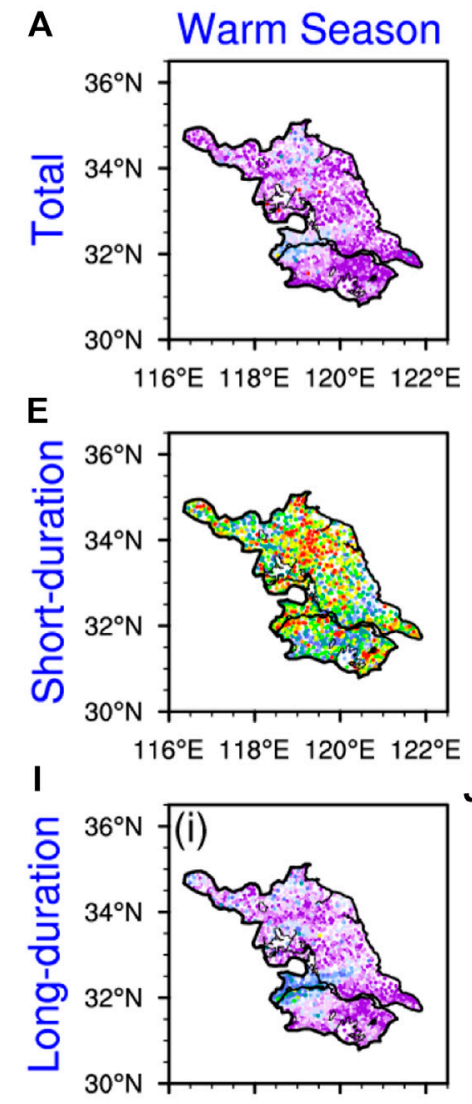

$116^{\circ} \mathrm{E} 118^{\circ} \mathrm{E} 120^{\circ} \mathrm{E} 122^{\circ} \mathrm{E}$

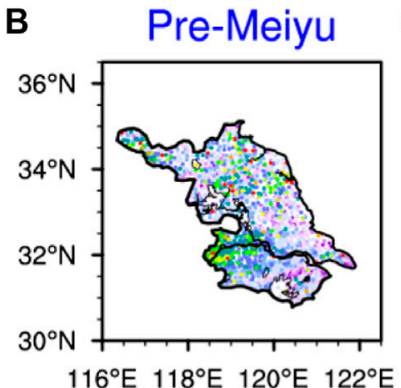

\section{$\mathrm{F}$}

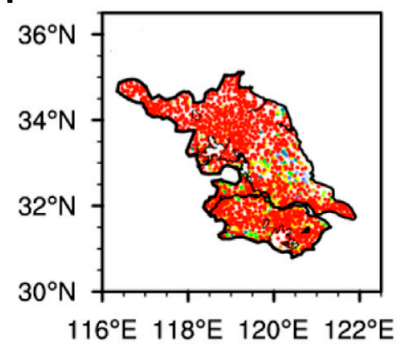

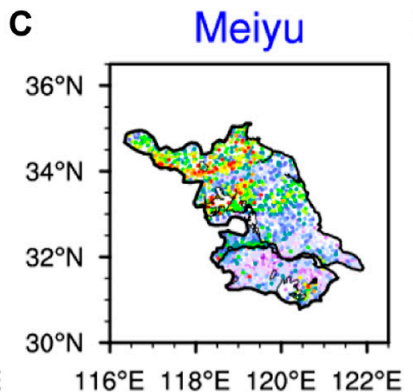

\section{G}

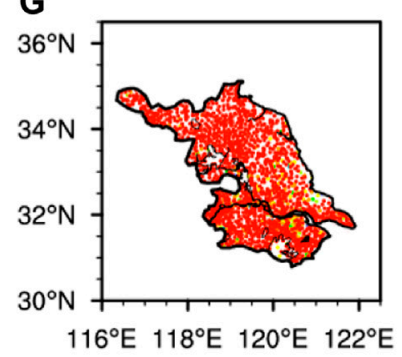

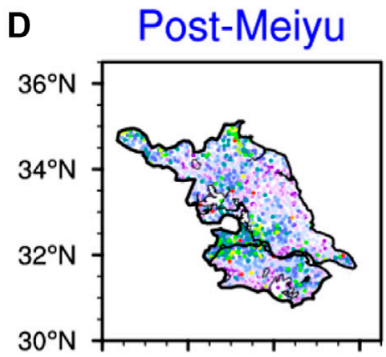

$116^{\circ} \mathrm{E} 118^{\circ} \mathrm{E} 120^{\circ} \mathrm{E} 122^{\circ} \mathrm{E}$

$\mathrm{H}$

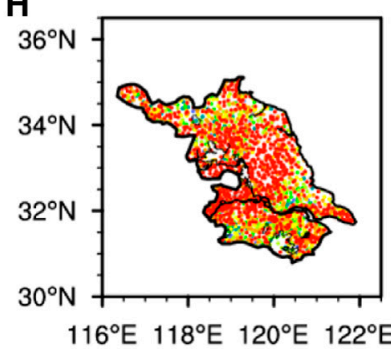

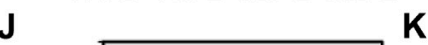

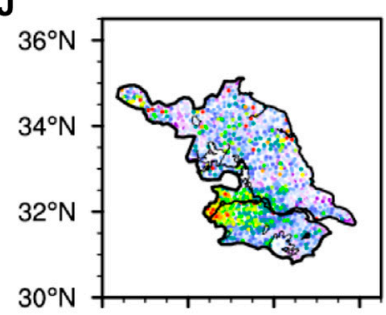

$116^{\circ} \mathrm{E} 118^{\circ} \mathrm{E} 120^{\circ} \mathrm{E} 122^{\circ} \mathrm{E}$

\section{$\mathrm{K}$}

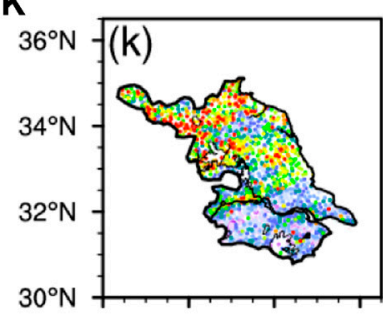

$116^{\circ} \mathrm{E} 118^{\circ} \mathrm{E} 120^{\circ} \mathrm{E} 122^{\circ} \mathrm{E}$
L

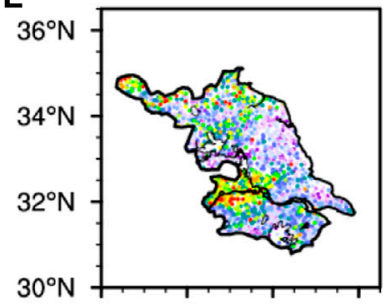

$116^{\circ} \mathrm{E} 118^{\circ} \mathrm{E} 120^{\circ} \mathrm{E} 122^{\circ} \mathrm{E}$

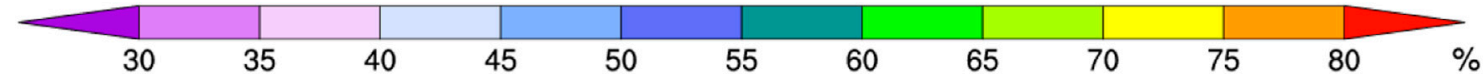

FIGURE 7 | Spatial distributions of PDV for total PA (A-D), short-duration rainfall PA (E-H) and long-duration rainfall PA (G-I) in warm season and each sub-period of warm season (four rows separately represent Warm season, Pre-Meiyu, Meiyu and Post-Meiyu period) averaged over $2013-2017$.

duration, and short-duration rainfall during different subperiods of the warm season. During the whole warm season (Figure $\mathbf{8 A}$ ), relatively larger PPA $\left(>0.4 \mathrm{~mm} \mathrm{~h}^{-1}\right)$ is mainly located over the south side of JSYR with southward and northward decreasing trends. The strongest PPA is located over the southwest side of JSYR, and the PPA values gradually decrease northeastward from morning to midnight (Figures 8A, 9A). The PPA mainly occurs in the morning (afternoon to midnight) over the southwestern and central regions (northern and southeastern Jiangsu) during the entire warm season (Figure 9A). The spatial distribution and occurrence time of PPA during pre-Meiyu (Figures 8B, 9B) and Meiyu (Figures 8C, 9C) periods are similar to those during the entire warm season, and the PPA is much stronger during the Meiyu period. During the post-Meiyu period (Figure 8D), the PPA is relatively uniform and mainly occurs from noon to midnight (Figure 9D). For the long-duration rainfall, the spatial distribution of PPA (Figure 8I-L) is similar to that of the total rainfall. However, the PPA of long-duration rainfall is slightly weaker. During the entire warm season, the occurrence time of PPA is several hours later than that of the total rainfall over the north and southeast Jiangsu. However, during pre-Meiyu and Meiyu periods, the occurrence time of the total rainfall and the long-duration rainfall is almost consistent (Figures 9B, C, J, and K). From Figures 8E-H, 9E-H, PPA of the short-duration rainfall is much more uniformly distributed over Jiangsu and tends to occur in the nighttime (from noon to midnight) during the pre-Meiyu period (the entire warm season, and pre-Meiyu and post-Meiyu periods).

The diurnal cycles of the PA for the rainfall with different durations in the warm season and each subperiod are shown in Figure 10. The PA in the warm season shows two comparable diurnal peaks, with one in the morning and the other in the afternoon, determined by the morning peak of long-duration rainfall and the afternoon peak of short-duration rainfall (Figure 10A). The diurnal cycles of the PA also exhibit this pattern in both Meiyu and post-Meiyu periods. During the pre-Meiyu period (Figure 10B), the PA of long-duration rainfall and total rainfall is very close and has significantly consistent diurnal cycle features. The PA of short-duration rainfall is very weak during the whole day. Among the three subperiods, the PA of the rainfall with different durations is highest during the Meiyu period. During the Meiyu and post-Meiyu periods, the long-duration rainfall peaks in the morning, whereas the short-duration rainfall peaks in the afternoon, and the 

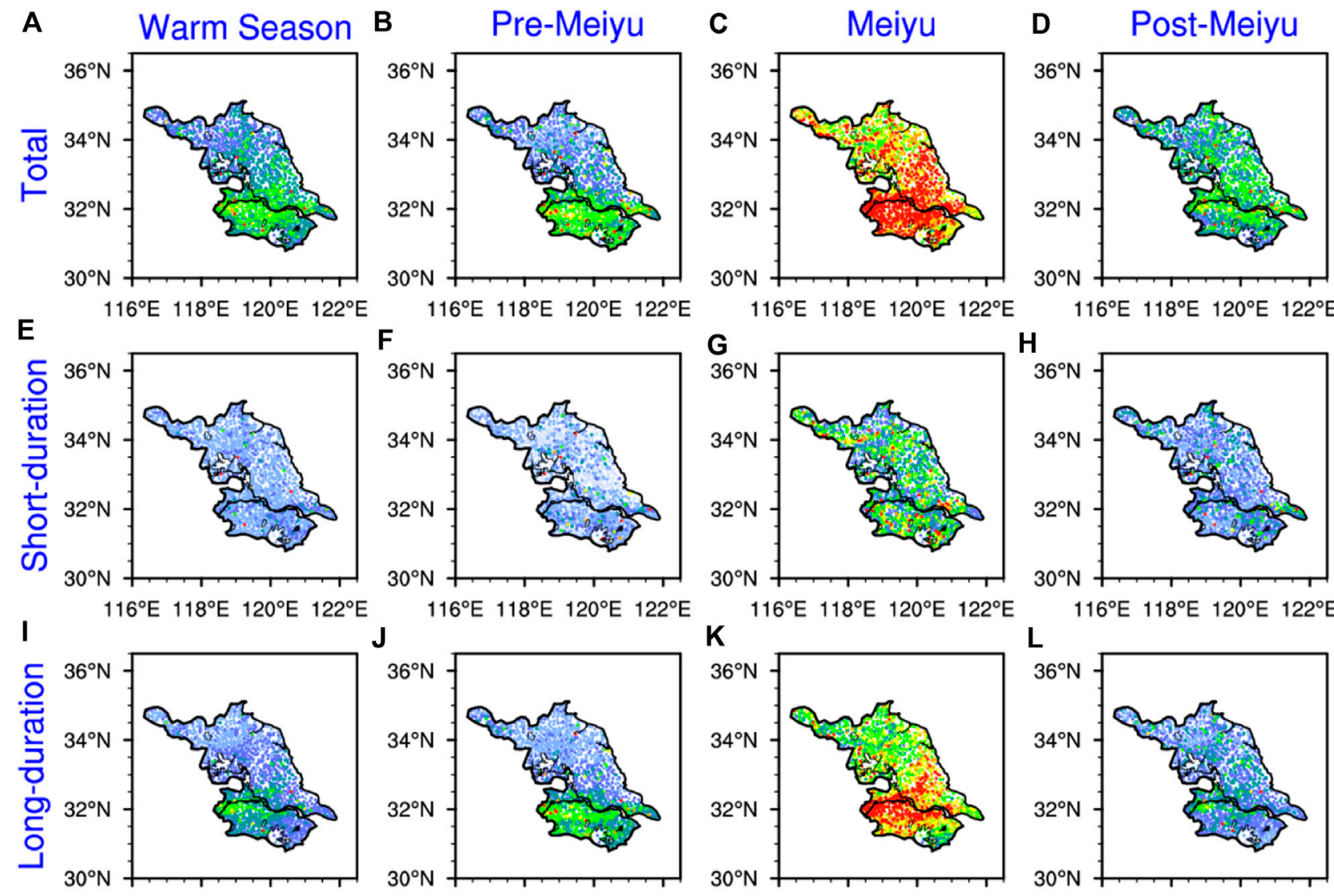

$116^{\circ} \mathrm{E} 118^{\circ} \mathrm{E} 120^{\circ} \mathrm{E} 122^{\circ} \mathrm{E}$

$116^{\circ} \mathrm{E} 118^{\circ} \mathrm{E} 120^{\circ} \mathrm{E} 122^{\circ} \mathrm{E}$
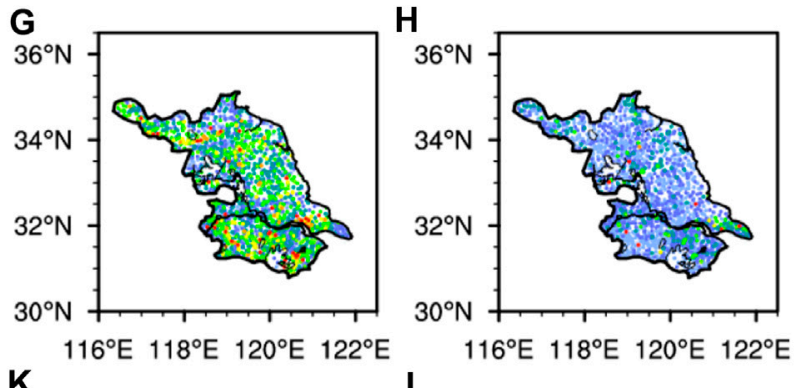

$\mathrm{K}$

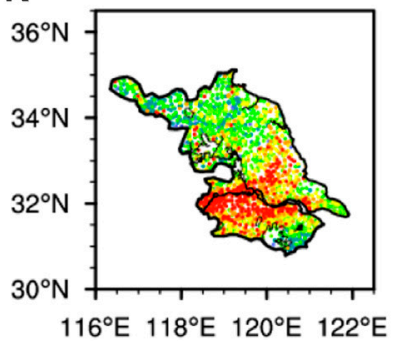

L

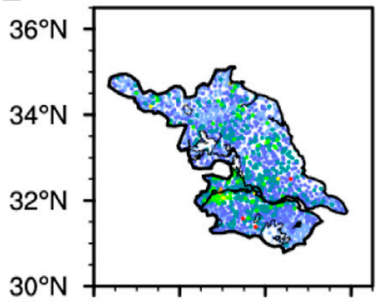

$116^{\circ} \mathrm{E} 118^{\circ} \mathrm{E} 120^{\circ} \mathrm{E} 122^{\circ} \mathrm{E}$

\begin{tabular}{lllllll|lll|l} 
& & & & & & & & & \\
\hline & 0.1 & 0.2 & 0.3 & 0.4 & 0.5 & 0.6 & 0.7 & $0.8 \quad \mathrm{~mm} \cdot \mathrm{h}$
\end{tabular}

FIGURE 8 | Spatial distributions of the diurnal peak of PA (PPA) for total rainfall (A-D), short-duration rainfall (E-H) and long-duration rainfall (G-I) in warm season and each sub-season of warm season (four rows separately represent Warm season, Pre-Meiyu, Meiyu and Post-Meiyu period) averaged over $2013-2017$.

diurnal PA peaks are lower than those of the long-duration rainfall. During pre-Meiyu and Meiyu periods, the PA of longduration rainfall is much higher than that of short-duration rainfall and largely contributes to the total PA.

The PA in the warm season presents a double diurnal peak pattern: one is in the morning and the other is in the afternoon, mostly contributed by the short-duration rainfall. The PA is higher during the daytime than the nighttime. From midnight to noon, the strong PA region extends westward and gradually increases along both sides of JSYR, and then it recedes eastward from the afternoon to evening. This is closely related to the diurnal variation of the low-level ascending movement. The afternoon peak of the PA is mainly due to the increase of precipitation intensity, which is probably related to the thermal convection initiation in the summer afternoon. During pre-Meiyu and Meiyu periods, precipitation is mainly contributed by long-duration rainfall controlled by the East Asia summer monsoon system, and there is a significant spatial difference in the diurnal variation of precipitation (Chen et al., 2005; Chen et al., 2010; Yuan et al., 2010; Wu et al., 2018).

\section{The Diurnal Cycle of the Synoptic-Scale Background}

The ECMWF ERA5 reanalysis data (Hersbach et al., 2020) with a horizontal resolution of $0.25 \times 0.25^{\circ}$ and time intervals of $1^{\circ}$ hour are used to analyze the synoptic features. The time-averaged horizontal water vapor flux and its divergence at the $850^{\circ} \mathrm{hPa}$ level and vertical velocity at the $500^{\circ} \mathrm{hPa}$ level are analyzed (Figure 11) to discuss the possible mechanisms related to the diurnal cycle of precipitation in Jiangsu (Simmonds et al., 1999). In the whole warm season, Jiangsu is mainly influenced by the southwestward water vapor flux. The water vapor flux and its divergence are strongest during the Meiyu period but weakest during the preMeiyu period. The water vapor flux divergence shows a diurnal variation over most areas, but it is nearly always positive to the south of Jiangsu, mainly due to the local hill topography. The water vapor mainly converges in the nighttime and diverges in the daytime over the inland areas during all periods (Figure 11), which is closely related to a nighttime southwesterly low-level jet (Zeng, et al., 2019). The strongest water vapor convergence occurs around the midnight (Figures 11A, E and M), except for several 

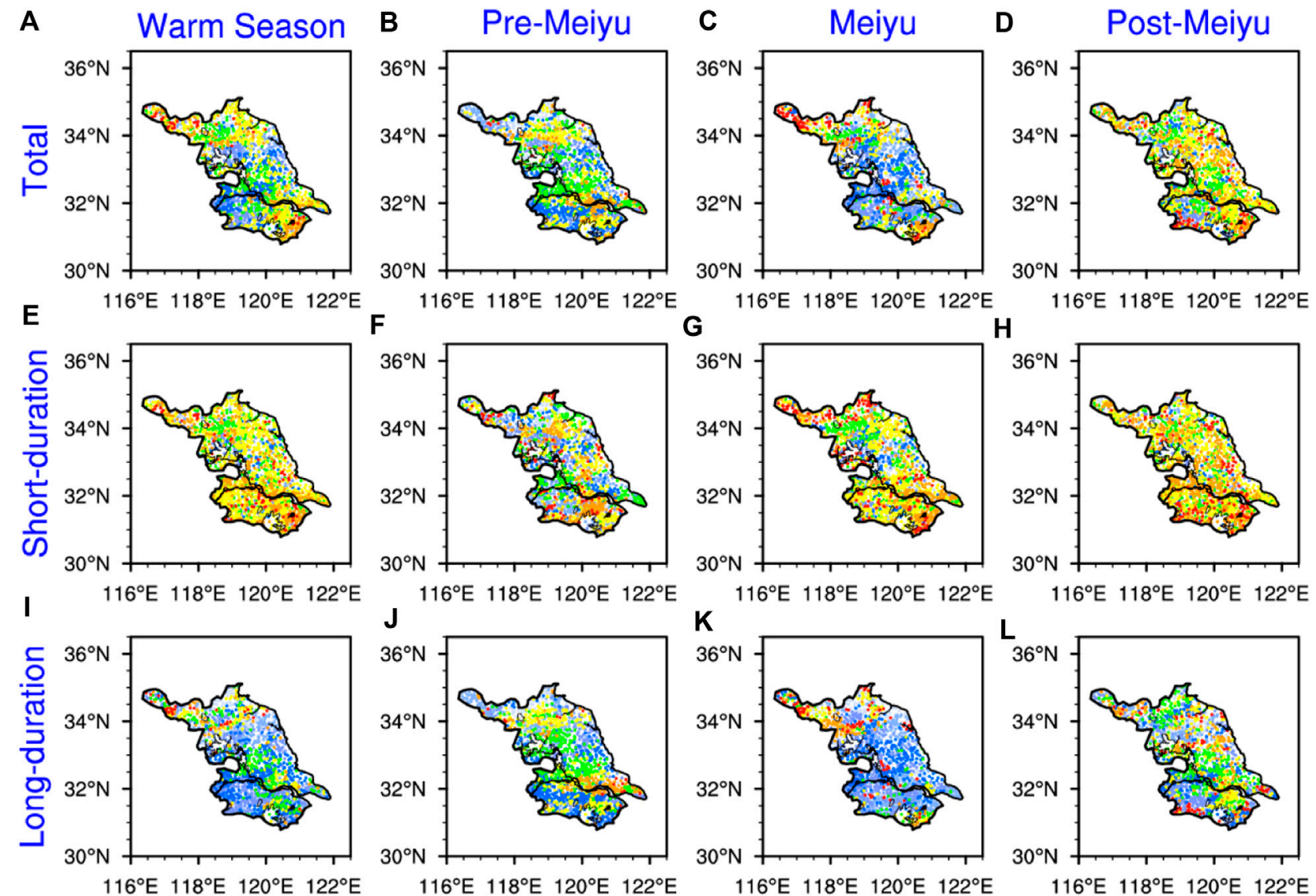

$116^{\circ} \mathrm{E} 118^{\circ} \mathrm{E} 120^{\circ} \mathrm{E} 122^{\circ} \mathrm{E}$
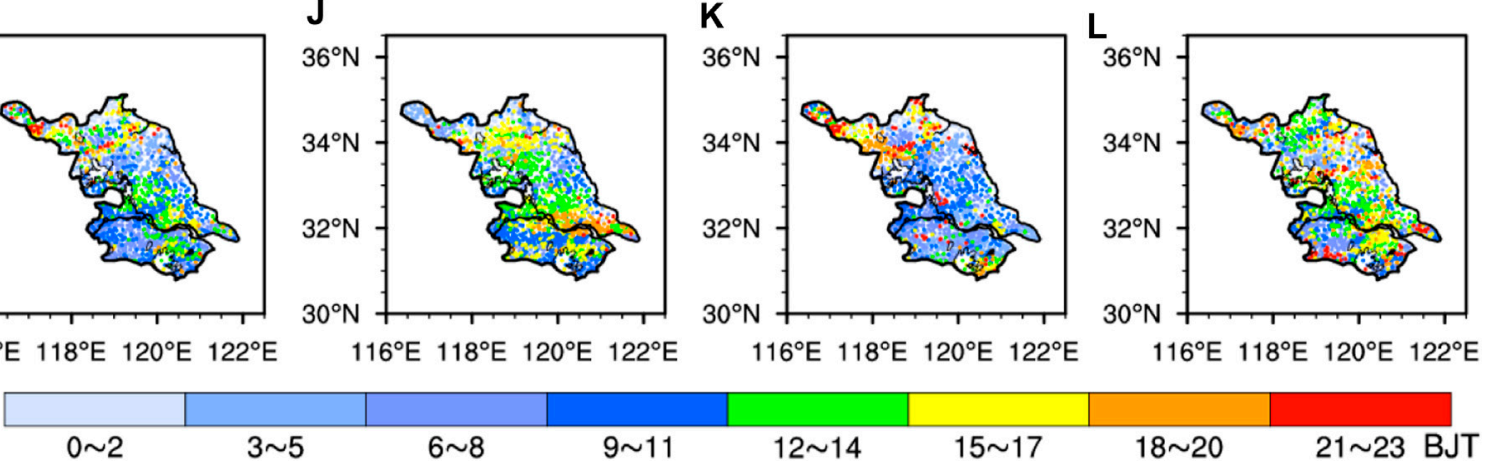

FIGURE 9 | Spatial distributions of the diurnal peak time of PA for total rainfall (A-D), short-duration rainfall (E-H) and long-duration rainfall (G-I) in warm season and each sub-season of warm season (four rows separately represent Warm season, Pre-Meiyu, Meiyu and Post-Meiyu period) over 2013-2017.

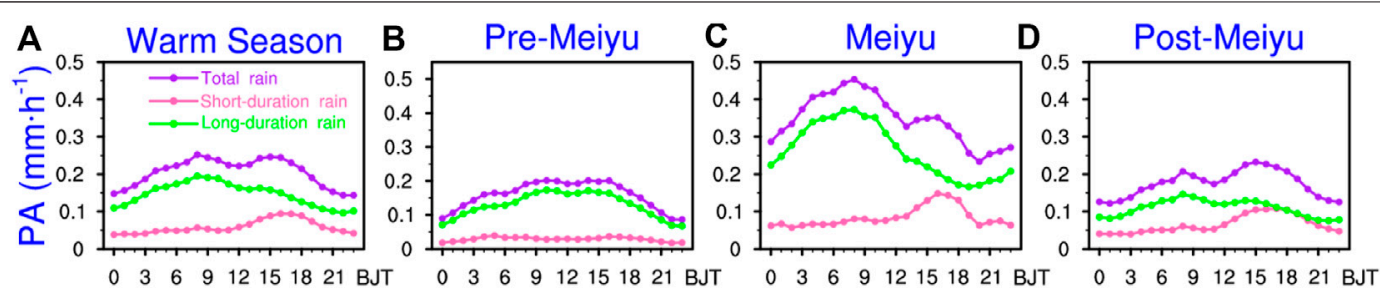

FIGURE 10 | Diurnal cycles of total PA and PA with different duration regionally averaged over Jiangsu in warm season and each sub-period of warm season (figures A-D separately represent Warm season, Pre-Meiyu, Meiyu and Post-Meiyu period) over 2013-2017.

hours later during the Meiyu period (Figure 11I). The strongest divergence occurs around the sunset (Figures 11C, 1G, K and O). The southwestward or southward water vapor flux gradually weakens from sunrise (Figures 11B, 1F, J and N) and then enhances from sunset (Figures 11C, 1G, $\mathbf{K}$ and $\mathbf{O}$ ). During the whole warm season (Figures 11A-D), water vapor convergence (divergence) and ascending (sinking) movements are consistent, corresponding to the long-duration precipitation diurnal cycles
(Figure 10A). During the pre-Meiyu period (Figures 11E-H), the water vapor flux and its convergence is weakest among the three subperiods, so the precipitation diurnal cycle is consistent with both the vapor water convergence and the ascending movement. But during Meiyu (Figure 11I-L) and post-Meiyu (Figure 11M-P) periods, the precipitation diurnal cycle is more consistent with the dynamic lift, indicated by the updraft on the $500 \mathrm{hPa}$ level, since the water vapor is very abundant. From the 

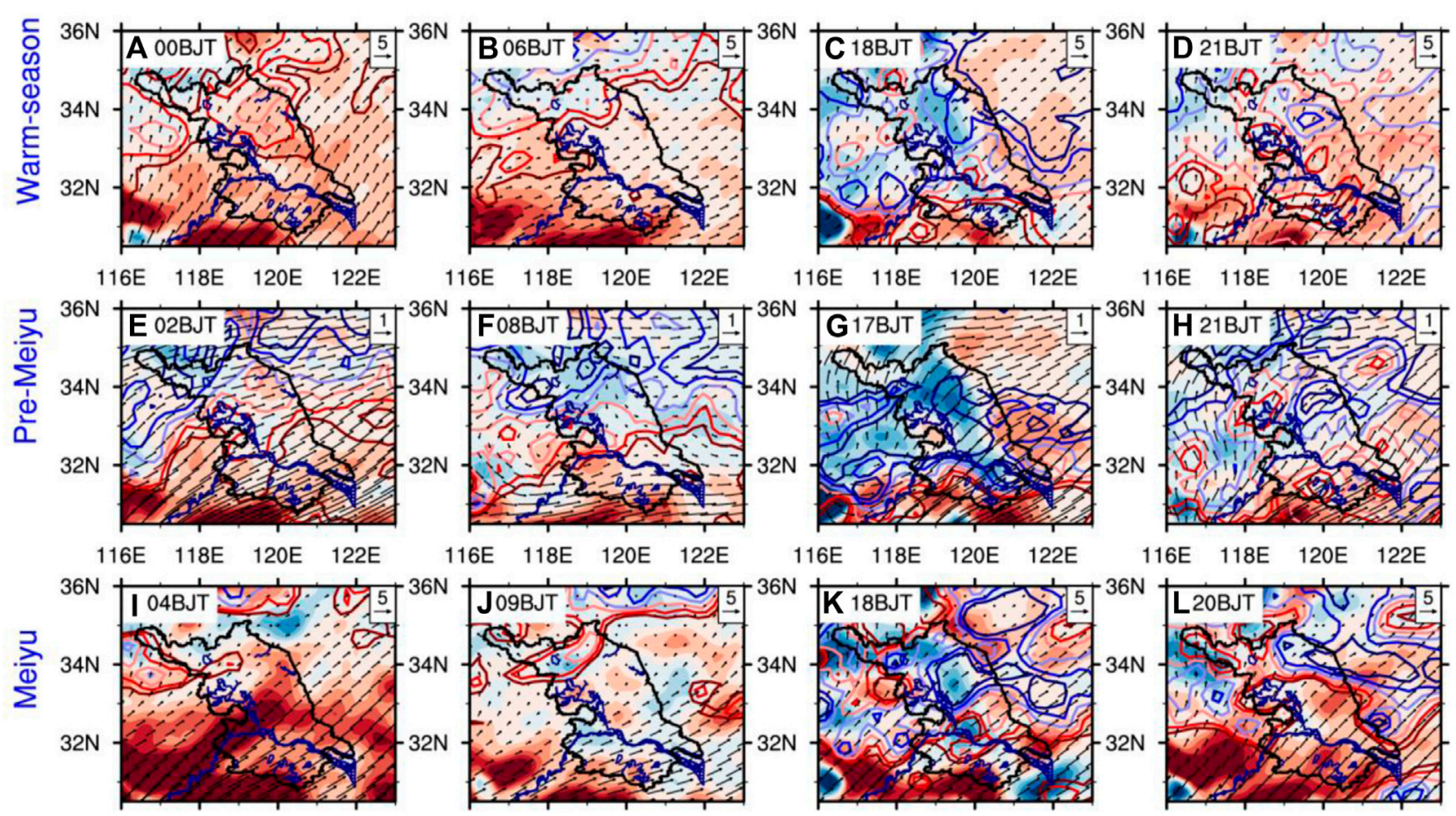

116E 118E 120E 122E

116E 118E 120E 122E
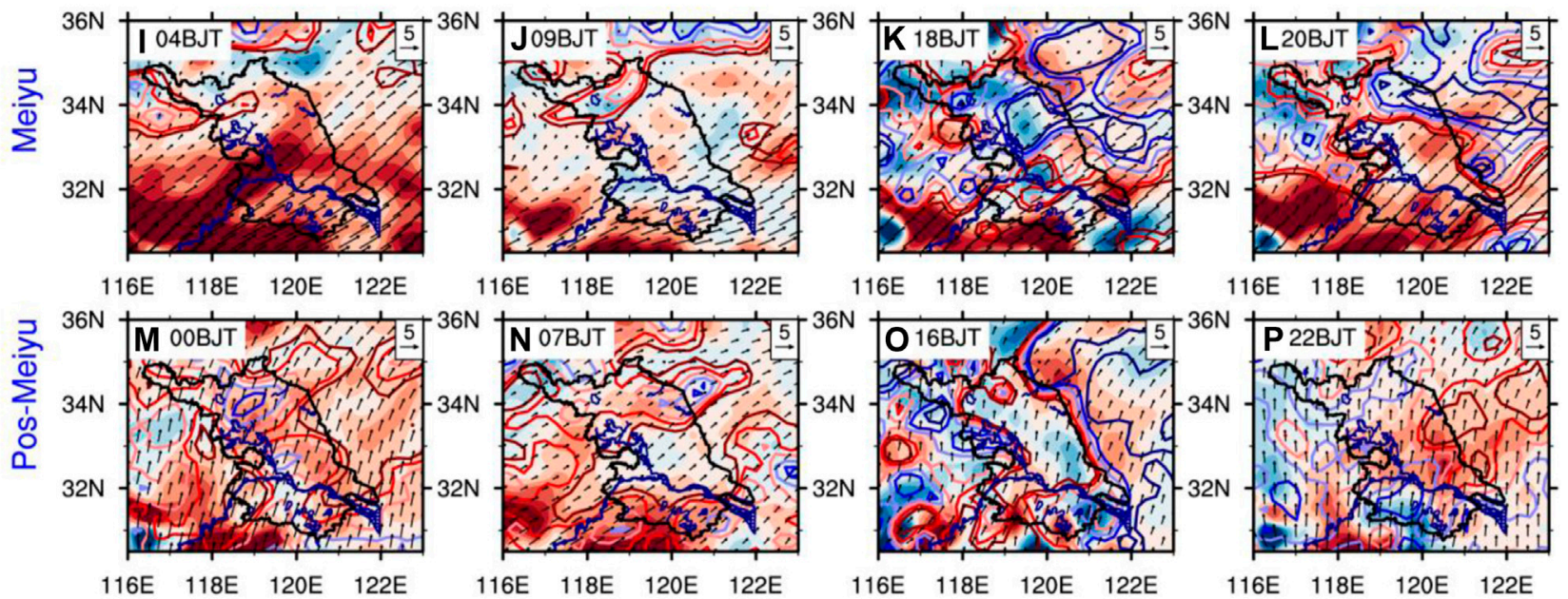

116E 118E 120E 122E

116E 118E 120E 122E

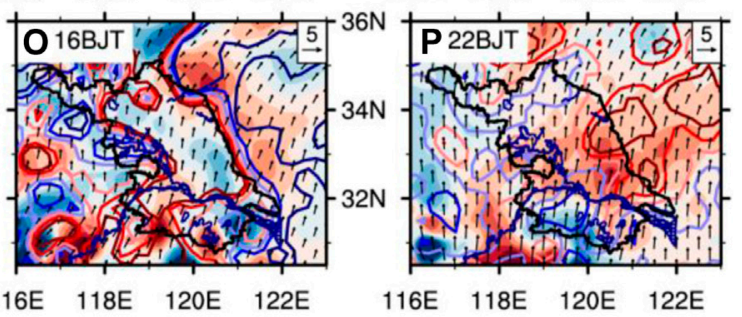

\begin{tabular}{lcccc|c|ccccc}
\hline-1 & -0.8 & -0.6 & -0.4 & -0.2 & 0 & 0.2 & 0.4 & 0.6 & 0.8 & 1
\end{tabular}

FIGURE 11 | The water vapor flux (arrows, units: $10^{-6} \mathrm{~kg} \mathrm{~s}^{-1} \mathrm{~m}^{-1} \mathrm{~Pa}^{-1}$ ) and its divergence (shading, units: $10^{-9} \mathrm{~kg} \mathrm{~s}^{-1} \mathrm{~m}^{-2} \mathrm{~Pa}{ }^{-1}$ ) at $850 \mathrm{hPa}$ and vertical velocity (contours, units: $\mathrm{m} \cdot \mathrm{s}^{-1}$, red means rising and blue means sinking, darker color means larger amplitude) at $500 \mathrm{hPa}$ derived from the ERA5 data at different hour of a day during warm season (A-D), Pre-Meiyu (E-H), Meiyu (G-I) and Post-Meiyu (M-P) periods over 2013-2017.

analysis of climatic average, the diurnal variations of water vapor convergence and ascending movement mainly affect the longduration precipitation. The interaction between the Dabie Mountains and a nighttime boundary layer low-level jet due to the inertial oscillation mechanism is shown to be responsible for the precipitation diurnal peak (Fu P. et al., 2019). The shortduration precipitation is mainly caused by a local thermal and dynamic factor. For example, during the post-Meiyu period, the diurnal variation of the land-sea circulation is shown by the vertical movement, especially from the afternoon (Figure 110) to evening (Figure 11P). In the afternoon (Figures 11C, 1G, K and $\mathbf{O})$, the thermal and dynamic conditions over big cities and lakes are obviously different from those of the surrounding areas.

The PA seems to begin developing locally since 03:00 BJT in most areas of Jiangsu, accompanied by the initiation of the lowlevel convergence and the acceleration of the anomalous southwest moisture flux (Wu et al., 2018). During the postMeiyu period, Jiangsu is under control of the western Pacific subtropical high. The precipitation is mainly ascribed to a strong local thermal convection caused by the solar heating in the afternoon, whereas the spatial variation of the precipitation diurnal cycle is small (Yuan et al., 2012; Wu et al., 2018).

From the pre-Meiyu through Meiyu to post-Meiyu period, the main rain belt moves northward, and the strongest PA occurs during the Meiyu period due to the northward shift of East Asia summer monsoon (Ding, 1992). The total rainfall mainly results from the long-duration rainfall determined by the summer monsoon circulation during the entire warm season. The contribution of the rainfall with a long (short) duration to the total rainfall over most Jiangsu shows distinctly sub-seasonal variation with a decreasing (increasing) trend from pre-Meiyu through Meiyu to post-Meiyu. The short-duration rainfall is 

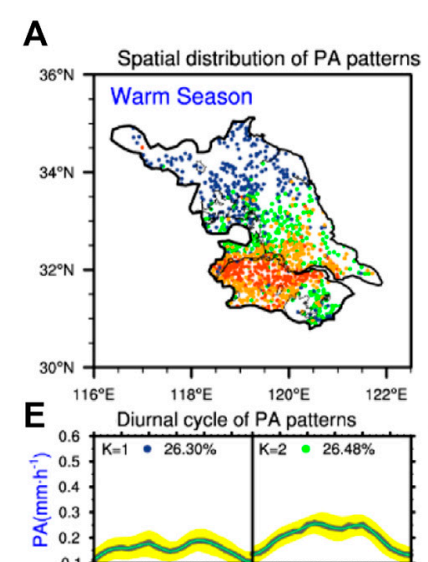

$\begin{array}{lllllllllllll}0.1 & 4 & 8 & 12 & 16 & 20 & 0 & 4 & 8 & 12 & 16 & 20 & \text { BJ }\end{array}$

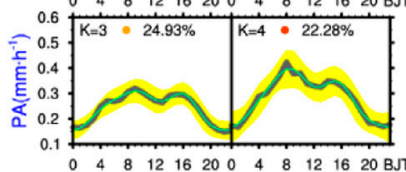

\section{B}
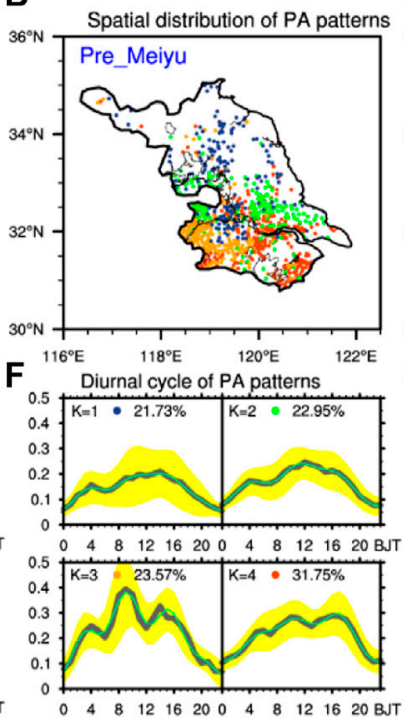

C

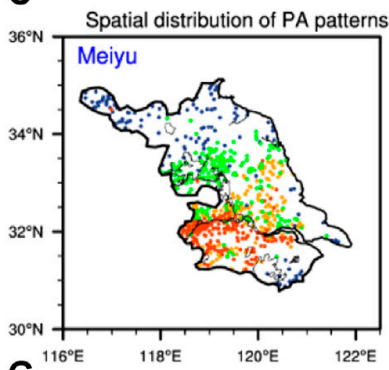

$\mathbf{G}^{116^{\circ} \mathrm{E}}$ Diurnal cycle of PA patterns ${ }^{122^{\circ} \mathrm{E}}$
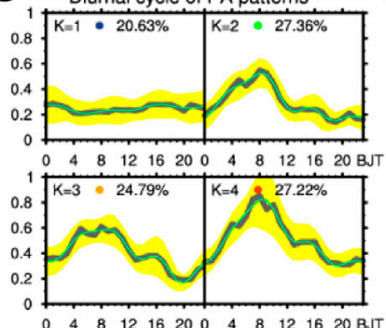

D

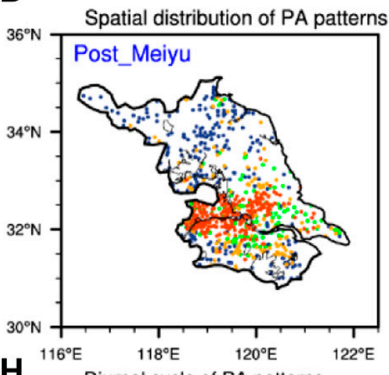

H ${ }^{116^{\circ} \mathrm{E} \quad 118^{\circ} \mathrm{E} \quad 120^{\circ} \mathrm{E}}$ Diurnal cycle of PA patterns

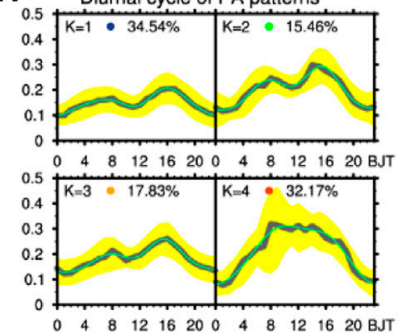

FIGURE 12 | Spatial distributions of PA patterns and their corresponding diurnal cycles along with the standard deviation of the PA among the stations belonging to a given cluster (shaded in yellow) in Jiangsu during different periods. The marks of PA patterns K (A-D) are labeled (E-H). Percentage (E-H) indicates the ratio of the station numbers of each PA pattern $\mathrm{K}$ to the total stations where the total daily variance is well explained by the first four harmonics. The grey (green) lines (E-H) show the diurnal cycles of PA with selected (all) stations.

mainly affected by the underlying surface thermal conditions and contributes less to the total rainfall compared to the longduration rainfall. During the Meiyu and post-Meiyu periods, the diurnal variation of precipitation is more consistent with the dynamic lift due to the abundant water vapor. But during the preMeiyu period, the diurnal variation of precipitation is more related to the water vapor convergence. Thus, the precipitation diurnal variation is closely related to the inertial oscillation of a nighttime southwesterly low-level jet with abundant moisture during the whole warm season.

\section{Results of the Cluster Analysis for the PA Diurnal Cycles}

Based on the fuzzy C-means cluster analysis mentioned in Data and Method, the representative patterns of PA diurnal cycles at the stations where the daily variance is well explained by the first four harmonics in different periods are shown in Figure 12. The gray (green) lines show the diurnal cycles of PF derived from the first three harmonics of Fourier analysis (original data). The gray line is very close to the green line, implying that the harmonics analysis can well reflect the raw data. The results of the cluster analysis show the typical patterns of precipitation diurnal variation and their spatial distributions.

The diurnal cycles of the PA during the warm season (Figures 12A, E) are mainly contributed by the first three harmonics over most Jiangsu. The largest amplitude of the diurnal cycle of precipitation appears in the western part of the south bank of JSYR including Nanjing City, and the lowest was observed over the plain on the east side of Lake Hongze. The PA pattern $\mathrm{K}=1$ is mainly located over the plain in northern Jiangsu. The PA pattern $\mathrm{K}=2$ is mainly situated over central Jiangsu, the regions east to
Lake Taihu, and southeastern coastal regions. The PA pattern $\mathrm{K}=3$ is mainly located over the narrow plain area on the north side of JSYR, most hill regions in southwest Jiangsu. The PA pattern $\mathrm{K}=$ 4 is situated over the regions south to JSYR, including Nanjing City. The PA patterns exhibit zonal features. The largest diurnal cycle amplitude of precipitation is along the Yangtze River, and the amplitude gradually decreases to the north and south, and the corresponding diurnal cycles gradually increase southward. This is probably mainly attributed to the local forcing of the underlying surface imbedded in the southwest monsoonal flow (Chen et al., 2009b; Chen G. et al., 2013). These four patterns exhibit both morning peaks and afternoon peaks, with consistent morning peaks occurring around 08:00BJT. The afternoon peaks of PA patterns $\mathrm{K}=1-3$ occur about 2-3 h delay relative to that of $\mathrm{PA}$ pattern $\mathrm{K}=4$. The $\mathrm{PA}$ for pattern $\mathrm{K}=4$ (1) is the highest (lowest), indicating that the PA increases southward. During each subperiod (Figures 11B-D and F-H), the PA patterns along JSYR are the most distinct with the highest corresponding PA value, and some other significant PA patterns are located over the east side of Lake Hongze (Figures 12B, C) and Lake Taihu (Figure 12B), indicating that the Yangtze River, big cities, and lakes severely affect the PA diurnal cycles. During the post-Meiyu period, the PA pattern and its corresponding diurnal cycle in Nanjing and its downstream areas are most distinctive.

In the pre-Meiyu period, the two patterns of $\mathrm{K}=1$ and $\mathrm{K}=2$ are similar, and their spatial distributions are also very close. Nanjing City and the southeast area showed $\mathrm{K}=3$ pattern, with three obvious peaks, and the largest peak appears in the morning. Suzhou City on the east side of Lake Taihu and Wuxi on the northwest side of Lake Tai are covered by pattern $\mathrm{K}=4$ with peak in the evening. During the Meiyu period, the area covered by $\mathrm{K}=1$ 
pattern is very small, mainly on the east side of Taihu Lake and the northern mountainous area, which shows the little diurnal cycle. Pattern $\mathrm{K}=2$ is over the plain in the east and south sides of Lake Hongze. Pattern $\mathrm{K}=3$ is over the plain area of central Jiangsu. Pattern $\mathrm{K}=4$ is over the regions west end of south to JSYR, including Nanjing City. The time characteristics of the diurnal cycles of $K=2,3$, and 4 are similar, and the amplitude of $K=4$ is the largest. In the post-Meiyu period, in terms of spatial distribution, $\mathrm{K}=1$ is mainly over the plains from the east bank of Hongze Lake to the coast. $\mathrm{K}=2$ and $\mathrm{K}=3$ patterns are intertwined and difficult to be distinguished. $K=4$ is distributed in Nanjing City and northeast downwind area. The diurnal cycles of pattern $K=1,2$, and 3 are similar, with two peaks in the day and the highest in the afternoon. The amplitude of $K=1$ is the lowest, and the amplitude of $K=3$ is the highest. $K=4$ shows a unique diurnal cycle. The PA is high throughout the day, and the peak appears in the morning.

Many features of precipitation are closely related to the underlying surface over Jiangsu. The distributions of four typical patterns of PA diurnal variation identified by the fuzzy C-means cluster analysis are basically zonally distributed and related to the underlying surface, such as JSYR, big cities, Lake Hongze, Lake Taihu, and coastal areas. Although having the same underlying surface type, Nanjing and Suzhou, and Hongze Lake and Taihu Lake do not show the same precipitation pattern, and the features of diurnal cycles of precipitation are not consistent because precipitation in Suzhou is influenced by a combination of urban effects and lake and land effects. The strongest precipitation diurnal variability is located over Nanjing City and its downwind regions. Large PF is located over both sides of JSYR. The PPA mostly occurs during the afternoon to the night over Jiangsu but occurs in the early morning over the southwestern hilly area, Nanjing City, east side of Lake Hongze, and the northern coastal region during the warm season. Nanjing locates in the downwind areas of the Yangtze River Valley between the Mountain Dabie and the Mountain Huangshan. This orographic effect accelerates lowlevel southwest flow which carries abundant moisture fluxes ( $\mathrm{He}$ and Zhang, 2010; Bao et al., 2011; Wu et al., 2018). Over Nanjing, the urban heat island induced low-level heating strengthens the ascending movement and leads to a deeper boundary layer with large CAPE in the afternoon (Zhang et al., 2017), contributing to form and intensify precipitation. The strengthened ascending movement can propagate downwind of the Nanjing city under the condition of environmental wind. Then the precipitation is intensified in the downwind of Nanjing. For another big city such as Suzhou, which locates to the east side (downwind direction) of Lake Taihu, the air mass generated by the nighttime lake-land circulation moves downwind and produces more nighttime precipitation there; thus, the precipitation and diurnal variation of precipitation are different from those of Nanjing.

\section{SUMMARY AND DISCUSSION}

In this work, the hourly rain gauge data with a high spatial resolution are used for the statistical analysis of diurnal cycles and spatial distribution of precipitation during the warm season in
Jiangsu. Furthermore, four typical patterns of PF diurnal variation in the warm season are identified by the fuzzy C-means cluster analysis. Main findings are shown as follows:

The climatic mean precipitation shows significant diurnal and spatial variations. The spatial distributions of precipitation show zonal characteristics over Jiangsu Province during the warm season. The precipitation center is located over the south side of JSYR. The Yangtze River seems like a barrier to the northward spread of rainfall. The spatial distribution of the total rainfall is strongly influenced by the Meiyu rainfall.

The precipitation presents a double diurnal peak pattern, with the morning peak produced by the long-duration rainfall and the afternoon peak mostly contributed by the short-duration rainfall. The diurnal cycle of the total rainfall is mainly attributed by the long-duration rainfall.

During pre-Meiyu and Meiyu periods, precipitation is mainly contributed by long-duration rainfall and more controlled by the synoptic scale background circulation. During post-Meiyu periods, precipitation is mainly contributed by short-duration rainfall, and it is more related to underlying surface such as Nanjing City, Lake Taihu, Lake Hongze, and hills. Although both Nanjing and Suzhou are big cities, they have obvious differences according to C-means analysis. The influence of the coupled circulation between Lake Taihu and Suzhou urban on the precipitation in Suzhou causes significant difference from that of Nanjing. The precipitation on the east coast of Hongze Lake and the east coast of Taihu Lake also shows different features. This is related to the fact that they are in different synoptic scale background circulations.

In the middle and lower reaches of the Yangtze River, the precipitation diurnal variation is closely related to the southwesterly low-level jet and its inertial oscillation (Zeng, et al., 2019; Fu X. et al., 2019). But specific to Jiangsu, the mechanism that affects the precipitation diurnal variation is more complicated. Although they are all located in eastern China, the precipitation diurnal cycles and spatial distribution of Jiangsu are different from those of Shandong and Fujian. In Shandong, the precipitation is affected by the monsoon and land-sea effect and shows an obviously decreasing trend from the southeast coast to the northwest inland (Zhuo et al., 2014). However, the precipitation diurnal cycles in Fujian are significantly affected by the terrain elevation and distance to coast (Zhang et al., 2017). In Jiangsu, the terrain is much flatter and the average elevation is very low. Therefore, the diurnal variation characteristics of precipitation in Jiangsu show obvious climatic zonal distributions. The precipitation diurnal cycles over Jiangsu in the warm season are also affected by the local underlying surface, such as Yangtze River, coastal areas, lakes, and big cities. However, the underlying physical mechanisms of precipitation diurnal cycles over Jiangsu related to the dynamical and thermal forcing are complex and remain as controversial questions. Based on more observations and simulations with high resolution, these issues should be further revealed in the future.

\section{DATA AVAILABILITY STATEMENT}

The datasets presented in this article are not readily available because raw data supporting the conclusions of this article is 
high precision. High spatial and temporal resolution observations are confidential data and cannot be made public according to the data management regulation. Requests to access the datasets should be mailed to corresponding author, anhuang@nju.edu.cn.

\section{AUTHOR CONTRIBUTIONS}

$\mathrm{AH}$ provided the idea and edited the manuscript. The other authors contributed the analysis and writing.

\section{REFERENCES}

Bao, X., Zhang, F., and Sun, J. (2011). Diurnal Variations of Warm-Season Precipitation East of the Tibetan Plateau over China. Mon. Wea. Rev. 139, 2790-2810. doi:10.1175/MWR-D-11-00006.1

Bowman, K. P., and Fowler, M. D. (2015). The Diurnal Cycle of Precipitation in Tropical Cyclones. J. Clim. 28, 5325-5334. doi:10.1175/JCLI-D-14-00804.1

Brito, S. S. d. B., and Oyama, M. D. (2014). Daily Cycle of Precipitation over the Northern Coast of Brazil. J. Appl. Meteorol. Climatol. 53 (11), 2481-2502. doi:10.1175/JAMC-D-14-0029.1

Carbone, R. E., Tuttle, J. D., Ahijevych, D., and Trier, S. B. 2002. Inferences of Predictability Associated with Warm Season Precipitation Episodes. J. Atmos. Sci., 59 (13), 2033-2056. doi:10.1175/1520-0469(2002)059<2033:IOPAWW >2.0.CO;2

Chen, G. T.-J., Wang, C.-C., and Lin, D. T.-W. (2005). Characteristics of Low-Level Jets over Northern Taiwan in Mei-Yu Season and Their Relationship to Heavy Rain Events. Mon. Wea. Rev. 133 (1), 20-43. doi:10.1175/MWR-2813.1

Chen, G., Sha, W., and Iwasaki, T. (2009a). Diurnal Variation of Precipitation over southeastern China: Spatial Distribution and its Seasonality. J. Geophys. Res. 114, D13103. doi:10.1029/2008JD011103

Chen, G., Sha, W., and Iwasaki, T. (2009b). Diurnal Variation of Precipitation over southeastern China: 2. Impact of the Diurnal Monsoon Variability. J. Geophys. Res. 114, D21105. doi:10.1029/2009JD012181

Chen, H., Yu, R., Li, J., Yuan, W., and Zhou, T. (2010). Why Nocturnal LongDuration Rainfall Presents an Eastward-Delayed Diurnal Phase of Rainfall Down the Yangtze River Valley. J. Clim. 23 (4), 905-917. doi:10.1175/ 2009JCLI3187.1

Chen, M., Wang, Y., Gao, F., and Xiao, X. (2012). Diurnal Variations in Convective Storm Activity over Contiguous North China during the Warm Season Based on Radar Mosaic Climatology. J. Geophys. Res. 117, D20115. doi:10.1029/ 2012JD018158

Chen, C.-S., Lin, Y.-L., Zeng, H.-T., Chen, C.-Y., and Liu, C.-L. (2013). Orographic Effects on Heavy Rainfall Events over Northeastern Taiwan during the Northeasterly Monsoon Season. Atmos. Res. 122, 310-335. doi:10.1016/ j.atmosres.2012.10.008

Chen, G., Sha, W., Sawada, M., and Iwasaki, T. (2013). Influence of Summer Monsoon Diurnal Cycle on Moisture Transport and Precipitation Over Eastern China. J. Geophys. Res. Atmos. 118 (8), 3163-3177. doi:10.1002/jgrd.50337

Dai, A., Giorgi, F., and Trenberth, K. E. (1999). Observed and Model-simulated Diurnal Cycles of Precipitation over the Contiguous United States. J. Geophys. Res. 104 (6), 6377-6402. doi:10.1029/98JD02720

Dai, A. (2001). Global Precipitation and Thunderstorm Frequencies. Part II: Diurnal Variations. J. Clim. 14 (6), 1112-1128. doi:10.1175/1520-0442(2001) 014<1112:gpatfp >2.0.co;2

Ding, Y. (1992). Summer Monsoon Rainfalls in China. J. Meteorol. Soc. Jpn. 70 (1B), 373-396. doi:10.2151/jmsj1965.70.1B_373

Fu, P., Zhu, K., Zhao, K., Zhou, B., and Xue, M. (2019). Role of the Nocturnal LowLevel Jet in the Formation of the Morning Precipitation Peak over the Dabie Mountains. Adv. Atmos. Sci. 36 (1), 15-28. doi:10.1007/s00376-018-8095-5

Fu, X., Yang, X. Q., and Sun, X. (2019). Spatial and Diurnal Variations of Summer Hourly Rainfall over Three Super City Clusters in Eastern China and Their Possible Link to the Urbanization. J. Geophys. Res. Atmos. 124, 5445-5462. doi:10.1029/2019JD030474

\section{FUNDING}

This work was jointly supported by the National Key Research and Development Program of China (grant no. 2018YFC1507503), the National Natural Science Foundation of China (grant nos. 41975081 and 41175086), Public Science and Technology Research Fund Projects of Meteorology (GYHY201306014), the Jiangsu University "Blue Project" outstanding young teachers training object, the Fundamental Research Funds for the Central Universities, and the Jiangsu Collaborative Innovation Center for Climate Change.

Fujibe, F. (1999). Diurnal variation in the frequency of heavy precipitation in Japan. J. Meteorol. Soc. Jpn. 77 (6), 1137-1149.

He, H., and Zhang, F. (2010). Diurnal Variations of Warm-Season Precipitation over Northern China. Mon. Wea. Rev. 138 (4), 1017-1025. doi:10.1175/ 2010MWR3356.1

Hersbach, H., Bell, B., Berrisford, P., Hirahara, S., Horányi, A., Muñoz-Sabater, J., et al. (2020). The ERA5 Global Reanalysis. Q.J.R. Meteorol. Soc. 146, 1999-2049. doi:10.1002/qj.3803

Huang, W.-R., and Chang, Y.-H. (2018). Characteristics and Mechanisms of the Diurnal Variation of winter Precipitation in Taiwan. Int. J. Climatol 38, 3058-3068. doi:10.1002/joc.5482

Huang, W.-R., and Wang, S.-Y. (2014). Impact of Land-Sea Breezes at Different Scales on the Diurnal Rainfall in Taiwan. Clim. Dyn. 43, 1951-1963. doi:10.1007/s00382-013-2018-Z

Jiang, Z., Zhang, D.-L., Xia, R., and Qian, T. (2017). Diurnal Variations of Presummer Rainfall over Southern China. J. Clim. 30 (2), 755-773. doi:10.1175/JCLI-D-15-0666.1

Kikuchi, K., and Wang, B. (2008). Diurnal Precipitation Regimes in the Global Tropics*. J. Clim. 21 (11), 2680-2696. doi:10.1175/2007JCLI2051.1

Li, J., Yu, R., and Zhou, T. (2008). Seasonal Variation of the Diurnal Cycle of Rainfall in Southern Contiguous China. J. Clim. 21, 6036-6043. doi:10.1175/2008jcli2188.1

Li, W., Luo, C., Wang, D., and Lei, T. (2010). Diurnal Variations of Precipitation over the South China Sea. Meteorol. Atmos. Phys. 109 (1-2), 33-46. doi:10.1007/ s00703-010-0094-8

Mao, J., and Wu, G. (2012). Diurnal Variations of Summer Precipitation over the Asian Monsoon Region as Revealed by TRMM Satellite Data. Sci. China Earth Sci. 55 (4), 554-566. doi:10.1007/s11430-011-4315-x

Ogino, S.-Y., Yamanaka, M. D., Mori, S., and Matsumoto, J. (2016). How Much Is the Precipitation Amount over the Tropical Coastal Region? J. Clim. 29 (3), 1231-1236. doi:10.1175/JCLI-D-15-0484.1

Ohsawa, T., Ueda, H., Hayashi, T., Watanabe, A., and Matsumoto, J. (2001). Diurnal Variations of Convective Activity and Rainfall in Tropical Asia. J. Meteorol. Soc. Jpn. 79 (1), 333-352. doi:10.2151/jmsj.79.333

Sato, T., Miura, H., Satoh, M., Takayabu, Y. N., and Wang, Y. (2009). Diurnal Cycle of Precipitation in the Tropics Simulated in a Global Cloud-Resolving Model. J. Clim. 22 (18), 4809-4826. doi:10.1175/2009JCLI2890.1

Simmonds, I., Bi, D., and Hope, P. (1999). Atmospheric Water Vapor Flux and its Association with Rainfall overChina in Summer. J. Clim. 12, 1353-1367. doi:10.1175/1520-0442(1999)012<1353:awvfai>2.0.co;2

Surcel, M., Berenguer, M., and Zawadzki, I. (2010). The Diurnal Cycle of Precipitation from Continental Radar Mosaics and Numerical Weather Prediction Models. Part I: Methodology and Seasonal Comparison. Monthly Weather Rev. 138 (8), 3084-3106. doi:10.1175/2010MWR3125.1

Svensson, C., and Jakob, D. r. (2002). Diurnal and Seasonal Characteristics of Precipitation at an upland Site in Scotland. Int. J. Climatol. 22 (5), 587-598. doi:10.1002/joc.674

Takahashi, H. G., Yoshikane, T., Hara, M., Takata, K., and Yasunari, T. (2010). High-resolution Modelling of the Potential Impact of Land Surface Conditions on Regional Climate over Indochina Associated with the Diurnal Precipitation Cycle. Int. J. Climatol. 30, 2004-2020. doi:10.1002/joc.2119

Tang, Y., Huang, A., Tian, L., Sun, H., Qi, D., and Pei, F. (2016). Numerical Study on Summer Local Climatic Effect over Lake Taihu (In Chinese). J. Meteorol. Sci. 36 (5), 647-654. 
Twardosz, R. (2007). Seasonal Characteristics of Diurnal Precipitation Variation in Kraków (South Poland). Int. J. Climatol. 27 (7), 957-968. doi:10.1002/joc.1439

Wu, Y., Huang, A., Huang, D., Chen, F., Yang, B., Zhou, Y., et al. (2018). Diurnal Variations of Summer Precipitation over the Regions East to Tibetan Plateau. Clim. Dyn. 51 (11-12), 4287-4307. doi:10.3354/cr026139

Xue, M., Luo, X., Zhu, K., Sun, Z., and Fei, J. (2018). The Controlling Role of Boundary Layer Inertial Oscillations in Meiyu Frontal Precipitation and its Diurnal Cycles over China. J. Geophys. Res. Atmos. 123, 5090-5115. doi:10.1029/2018jd028368

Yang, G.-Y., and Slingo, J. (2001). The Diurnal Cycle in the Tropics. Mon. Wea. Rev. 129 (4), 784-801. doi:10.1175/1520-0493(2001)129<0784:tdcitt>2.0.co;2

Yang, P., Ren, G., Hou, W., and Liu, W. (2013). Spatial and Diurnal Characteristics of Summer Rainfall over Beijing Municipality Based on a High-Density AWS Dataset. Int. J. Climatol. 33, 2769-2780. doi:10.1002/joc.3622

Yaqub, A., Seibert, P., and Formayer, H. (2011). Diurnal Precipitation Cycle in Austria. Theor. Appl. Climatol. 103 (1-2), 109-118. doi:10.1007/s00704-010-0281-z

Yin, S., Chen, D., and Xie, Y. (2009). Diurnal variations of precipitation during the warm season over China. Int. J. Climatol. 29 (8), 1154-1170. doi:10.1002/ joc. 1758

Yokoi, S., Mori, S., Katsumata, M., Geng, B., Yasunaga, K., Syamsudin, F., et al. (2017). Diurnal Cycle of Precipitation Observed in the Western Coastal Area of Sumatra Island: Offshore Preconditioning by Gravity Waves. Mon. Wea. Rev. 145 (9), 3745-3761. doi:10.1175/MWR-D-16-0468.1

Yu, R., Zhou, T., Xiong, A., Zhu, Y., and Li, J. (2007a). Diurnal Variations of Summer Precipitation over Contiguous China. Geophys. Res. Lett. 34, L01704. doi:10.1029/2006GL028129

Yu, R., Xu, Y., Zhou, T., and Li, J. (2007b). Relation between Rainfall Duration and Diurnal Variation in the Warm Season Precipitation over central Eastern China. Geophys. Res. Lett. 34, a-n. doi:10.1029/2007GL030315

Yu, R., Li, J., Chen, H., and Yuan, W. (2014). Progress in Studies of the Precipitation Diurnal Variation over Contiguous China. J. Meteorol. Res. 28 (5), 877-902. doi:10.1007/s13351-014-3272-7

Yuan, W., Yu, R., Chen, H., Li, J., and Zhang, M. (2010). Subseasonal Characteristics of Diurnal Variation in Summer Monsoon Rainfall over Central Eastern China. J. Clim. 23 (24), 6684-6695. doi:10.1175/2010JCLI3805.1

Yuan, W., Yu, R., and Li, J. (2013). Changes in the Diurnal Cycles of Precipitation over Eastern China in the Past 40 Years. Adv. Atmos. Sci. 30 (2), 461-467. doi:10.1007/s00376-012-2092-x
Yuan, W., Yu, R., Zhang, M., Lin, W., Chen, H., and Li, J. (2012). Regimes of diurnal variation of summer rainfall over subtropical East Asia. J. Clim. 25 (9), 3307-3320. doi:10.1175/JCLI-D-11-00288.1

Yuan, W. (2013). Diurnal Cycles of Precipitation over Subtropical China in IPCC AR5 AMIP Simulations. Adv. Atmos. Sci. 30 (6), 1679-1694. doi:10.1007/ s00376-013-2250-9

Zeng, W., Chen, G., Du, Y., and Wen, Z. (2019). Diurnal Variations of Low-Level Winds and Precipitation Response to Large-Scale Circulations during a Heavy Rainfall Event. Mon. Wea. Rev. 147 (11), 3981-4004. doi:10.1175/mwr-d-19-0131.1

Zhang, W., Huang, A., Zhou, Y., Yang, B., Fang, D., Zhang, L., et al. (2017). Diurnal Cycle of Precipitation over Fujian Province during the Pre-summer Rainy Season in Southern China. Theor. Appl. Climatol 130, 993-1006. doi:10.1007/ s00704-016-1927-2

Zhou, T., Yu, R., Chen, H., Dai, A., and Pan, Y. (2008). Summer Precipitation Frequency, Intensity, and Diurnal Cycle over China: A Comparison of Satellite Data with Rain Gauge Observations. J. Clim. 21 (16), 3997-4010. doi:10.1175/ 2008jcli2028.1

Zhuo, H., Zhao, P., and Zhou, T. (2014). Diurnal Cycle of Summer Rainfall in Shandong of Eastern China. Int. J. Climatol. 34 (3), 742-750. doi:10.1002/ joc. 3718

Conflict of Interest: The authors declare that the research was conducted in the absence of any commercial or financial relationships that could be construed as a potential conflict of interest.

Publisher's Note: All claims expressed in this article are solely those of the authors and do not necessarily represent those of their affiliated organizations, or those of the publisher, the editors and the reviewers. Any product that may be evaluated in this article, or claim that may be made by its manufacturer, is not guaranteed or endorsed by the publisher.

Copyright (C) $2021 \mathrm{Mu}$, Huang, Wu, Xu, Zheng, Lin, Fang, Zhang, Tang and Cai. This is an open-access article distributed under the terms of the Creative Commons Attribution License (CC BY). The use, distribution or reproduction in other forums is permitted, provided the original author(s) and the copyright owner(s) are credited and that the original publication in this journal is cited, in accordance with accepted academic practice. No use, distribution or reproduction is permitted which does not comply with these terms. 